IZA DP No. 5811

Do Frictions Matter in the Labor Market? Accessions, Separations and Minimum Wage Effects

Arindrajit Dube

T. William Lester

Michael Reich

June 2011 


\title{
Do Frictions Matter in the Labor Market? Accessions, Separations and Minimum Wage Effects
}

\author{
Arindrajit Dube \\ University of Massachusetts, Amherst \\ and IZA \\ T. William Lester \\ University of North Carolina, Chapel Hill \\ Michael Reich \\ University of California, Berkeley \\ Discussion Paper No. 5811 \\ June 2011 \\ IZA \\ P.O. Box 7240 \\ 53072 Bonn \\ Germany \\ Phone: +49-228-3894-0 \\ Fax: +49-228-3894-180 \\ E-mail: iza@iza.org
}

\begin{abstract}
Any opinions expressed here are those of the author(s) and not those of IZA. Research published in this series may include views on policy, but the institute itself takes no institutional policy positions.

The Institute for the Study of Labor (IZA) in Bonn is a local and virtual international research center and a place of communication between science, politics and business. IZA is an independent nonprofit organization supported by Deutsche Post Foundation. The center is associated with the University of Bonn and offers a stimulating research environment through its international network, workshops and conferences, data service, project support, research visits and doctoral program. IZA engages in (i) original and internationally competitive research in all fields of labor economics, (ii) development of policy concepts, and (iii) dissemination of research results and concepts to the interested public.
\end{abstract}

IZA Discussion Papers often represent preliminary work and are circulated to encourage discussion. Citation of such a paper should account for its provisional character. A revised version may be available directly from the author. 


\title{
ABSTRACT
}

\section{Do Frictions Matter in the Labor Market? Accessions, Separations and Minimum Wage Effects}

\begin{abstract}
We measure labor market frictions using a strategy that bridges design-based and structural approaches: estimating an equilibrium search model using reduced-form minimum wage elasticities identified from border discontinuities and fitted with Bayesian and LIML methods. We begin by providing the first test of U.S. minimum wage effects on labor market flows and find negative effects on employment flows, but not levels. Separations and accessions fall among restaurants and teens, especially those with low tenure. Our estimated parameters of a search model with wage posting and heterogeneous workers and firms imply that frictions help explain minimum wage effects.
\end{abstract}

\section{NON-TECHNICAL SUMMARY}

What are the effects of minimum wage increases on the labor market? This is a question of long-standing interest to both economists and policy makers. Additionally, what can we learn about the nature of the labor market by looking at responses to minimum wage changes? In this paper, we compare areas in the US across state borders with different minimum wages and find some striking results: while increases in minimum wages do not seem to affect employment for workers in highly affected groups (those working in industries like restaurants, or teens generally), we do find that their earnings increase and their turnover rates fall sharply. We next use this set of results, along with new models of the labor market that focus on job search, to answer the following question: are there features of the labor market that deviate from a competitive "ideal" in important ways, and do these features help explain why minimum wages may tend to reduce turnover more than reduce jobs? Our study finds an affirmative answer to both these questions.

JEL Classification: $\quad$ C11, C63, J23, J38, J42, J63

Keywords: minimum wage, labor market flows, monopsony, Bayesian estimation

Corresponding author:

Arindrajit Dube

Department of Economics

University of Massachusetts-Amherst

1030 Thompson Hall

Amherst, MA 01003

USA

E-mail: adube@econs.umass.edu

\footnotetext{
* We thank Sylvia Allegretto, Joshua Angrist, Michael Ash, Orley Ashenfelter, David Autor, Gabriel Chodorow-Reich, Eric Freeman, Suresh Naidu, Andrew Shepard, Peter Skott and seminar participants at the Five Colleges Junior Faculty Workshop, University of Massachusetts Amherst, The New School for Social Research, Princeton University, MIT, University of California Berkeley, and the 2011 SOLE annual meetings for helpful suggestions and comments, Lynn Scholl for excellent research assistance and the Center for Equitable Growth and the Institute for Research on Labor and Employment, both at UC Berkeley, for research support.
} 


\section{Introduction}

The analysis of employment flows can provide important clues about the functioning of the labor market and shed new light on long-standing debates in economics. One such debate concerns the effects of minimum wage increases on employment levels, particularly for lowskilled workers. If the perfectly competitive benchmark is a good first approximation for the low-wage labor market, an increase in the minimum wage above a competitive equilibrium causes an unambiguous reduction in labor demand. If, however, there are substantial search frictions in the labor market, the intuition from the perfectly competitive model may be misleading. In models with search friction, equilibrium employment is constrained not only by labor demand, but also possibly by labor supply. Models with labor market frictions where firms have some wage-setting power can therefore explain why increasing the minimum wage might not necessarily reduce employment and, in some cases, may increase it.

At least since Card and Krueger (1995), search frictions have been posited to explain the seemingly anomalous result that minimum wage increases are not clearly associated with job losses. In Card and Krueger's dynamic monospony model, separation and recruitment rates are functions of the wage rate and the model allows positive firm-level labor supply elasticities. They argue that empirically plausible magnitudes of the labor supply elasticities facing a firm are consistent with small positive or zero effects of a minimum wage increase on employment levels. Subsequent firm-level studies, such as those surveyed by Ashenfelter, Farber and Ransom (2010), have indeed found labor supply elasticities consisent with substantial wage-setting power. But while the firm-level evidence on monopsony is important, these papers do not consider interaction among firms and workers, even though a minimum wage mandate affects a host of firms-and possibly differentially.

In the hypothetical case of a single firm facing a wage increase due to the policy, the labor supply elasticity facing the firm can be approximated as twice the elasticity of separations with respect to the average wage (Manning 2003). In this case, we could use the minimum wage as an instrument to estimate the separation elasticity of wage: the larger the separation elasticity, the more competitive is the market. However, this logic breaks down when many

firms are subjected to a common policy shock. On the one hand, even if the market is fairly competitive, separations may not fall as much because some other firms are also increasing wages. On the other hand, by narrowing the wage distribution, the minimum wage may reduce the odds of workers getting better offers-which is more likely to occur precisely when the market is initially less competitive and there is a wider wage dispersion. Therefore, to estimate the competitiveness of the labor market using minimum wage changes, we need additional information about how the policy affects earnings and employment, and some 
information about the wage distribution, along with a model of wage and employment determination in the labor market.

In this paper we use a relatively new dataset-the Quarterly Workforce Indicators (QWI)to estimate the reduced form minimum wage elasticities of average earnings, employment flows as well as employment levels, and then use these elasticities (along with a measure of equilibrium wage dispersion) to estimate the parameters of an equilibrium model with search frictions. The data permit us to estimate the responses of local labor-market-level separation, accession and turnover rates for high-impact demographic and industry groups: teens and restaurant workers. To our knowledge, these are the first estimates of the effect of minimum wage increases on employment flows using nationally representative U.S. data. Our estimated minimum wage elasticities are based on a border-discontinuity design that eliminates the spatial heterogeneity bias in many previous studies. We compare county pairs straddling a border with minimum wage differences, the approach taken in Dube, Lester and Reich (2010), hereafter DLR, who specifically look at the effect on restaurant employment levels.

Next, we examine the implications of our quasi-experimental findings within the context of an equilibrium search model with wage posting (Burdett and Mortensen 1998, hereafter BM), as extended by Bontemps, Robin and van den Berg (1999, hereafter BRV) to incorporate heterogeneous workers and firms. We estimate the parameters of the BM-BRV model with a limited information maximum likelihood approach. Specifically, we search over proposed parameters using a simulated annealing algorithm to maximize the likelihood of having observed the empirical distribution of the reduced-form elasticities and a measure of wage dispersion (minimum to mean wage ratio). We also estimate Bayesian posterior distributions for the parameters using Markov Chain Monte Carlo (MCMC).

We find striking evidence that separations, new hires, and turnover rates for teens and restaurant workers fall substantially following a minimum wage increase-with most of the reductions coming within the first year of the increase. We also find substantial positive effects on average earnings. But we do not find employment elasticities that are statistically distinguishable from zero for either teens or restaurant workers; nor do we find any evidence of labor-labor substitution within the restaurant workforce. When we estimate the model parameters to match these reduced-form elasticities, both point and interval estimates suggest a sizeable degree of wage-setting power, with firm-level labor supply elasticities in the 4 to 10 range. Our estimates of labor market frictions are consistent with the recent firm-level studies surveyed by Ashenfelter, Farber and Ransom (2010), and with parameters used in macroeconomic calibrations, such as Moscarini and Postel-Vinay (2009). We find that the increased competition from a minimum wage hike partly explains the small employment 
effects.

Our paper relates to two distinct literatures. First, a handful of papers have directly estimated the reduced-form effects of minimum wages on equilibrium turnover, separations, or tenure. Portugual and Cardoso (2006) find that teen separations fall substantially after a minimum wage increase in Portugal-results that are broadly similar to our own. However, the national-level policy change used for estimation makes it more like a single case study, raising concerns about both the identification strategy and inference. Furthermore, while they refer to the Burdett-Mortensen model as a possible explanation of their findings, they are not able to relate their reduced form estimates to a measure of labor market frictions- a key contribution of this paper. More recently, Brochu and Green (2011) use Canadian data and find that teen hires and layoffs decline in the year after a minimum wage increase but quits decline by much less; they find some reductions in employment levels as well. While quits are only around 38 percent of separations in their "low skilled" Canadian sample, JOLTS data for the U.S. indicate that quits accounted for 70 percent of the separations in the Accomodation and Food Services sector (mainly restaurants) during our sample period. This difference suggests that the layoff channel that Brochu and Green highlight has less relevance for the U.S. context. Unfortunately, the small number of Canadian provinces (and hence policy clusters) also raise serious concerns about identification and inference. For example their empirical strategy cannot rule out that heterogeneous spatial trends are driving some of their findings on layoffs and employment--which we show are quite important in the U.S. context. A few studies examine the effects of wage mandates on labor market flows in much more limited contexts. Dube, Naidu and Reich (2007) estimate employment and tenure effects in a single city-San Francisco-in response to a citywide wage mandate. The effects of "living-wage" laws on firm-based employee turnover have been studied in specific cities and sectors-for example, Fairris (2005); Howes (2005); and Reich, Hall and Jacobs (2005). ${ }^{1}$

Overall, compared to existing papers, we are able to estimate the responses of employment flows to minimum wage changes using much richer variation and a more credible identification strategy. And we directly assess the importance of labor market frictions by using these reduced-form results to recover the parameters of an equilibrium model.

Second, our paper relates to the literature that estimates minimum wage effects empirically within the context of labor market models with search frictions. Flynn (2006) and Flynn and Mabli (2008) estimate search models with binding minimum wages. Both papers estimate the parameters of the model using moment conditions (changes in cross-sectional proportions and transition probabilites in and out of jobs). ${ }^{2}$ The estimation strategy does

\footnotetext{
${ }^{1}$ See also the survey in Manning (2010).

${ }^{2}$ See also the survey by Chowdry et al. 2009.
} 
not exploit actual minimum wage variation; indeed, their estimation requires a stationary environment in which the minimum wage is fixed. A similar comment applies to empirical studies such as Eckstein and Wolpin (1990), Bontemps, Robin and van den Berg (1999) and Mortensen (2003). These studies also use variants of the Burdett-Mortensen model to document the importance of frictions in the labor market and the structural estimation in these papers are implemented without any direct use of the minimum wage variation. For example, Bontemps et al. (1999) invert the observed wage distribution to back out the distribution of productivity and then the other parameters in the model within a stationary environment. As a consequence, while the estimated models in these papers have important implications for minimum wage effects (including on observable dimensions such as employment level and turnover), the model-generated elasticities are not directly compared to their empirical counterparts. ${ }^{3}$ In contrast, matching the empirical and model-generated responses is precisely our approach here, and is similar in spirit to the estimation of macroeconomic models using impulse response matching (e.g., Christiano, Trabandt and Walentin 2010). Therefore, we see our paper as complementing existing structural evidence in the minimum wage literature.

Our paper also speaks to the debate on "design based" versus "model based" approaches to empirical work (e.g., Angrist and Pischke 2010, Sims 2010). In our case, carefully estimated reduced-form elasticities using a border-discontinuity design are critical for policy purposes. But we also use them to make inferences about model parameters and answer an economically important question that a purely reduced-form approach cannot answer: how important are labor market frictions in explaining the effects of the policy? We think this is a fruitful approach to bridge design and model based inference.

The rest of the paper is structured as follows. We discuss our dataset, sample and our identification strategy in Section 2 and report our reduced-form minimum wage elasticities in Section 3. Section 4 presents the equilibrium search model, and uses the reduced-form elasticities to estimate the parameters of the wage-posting model and Section 5 concludes.

\section{Data and Estimation of Reduced Form Elasticities}

\subsection{The Quarterly Workforce Indicators dataset}

The recent minimum wage literature in the U.S. has drawn primarily upon two datasets: the Quarterly Census of Employment and Wages, or QCEW (e.g., Dube, Lester and Reich

\footnotetext{
${ }^{3} \mathrm{~A}$ more recent example of a similar strategy as Bontemps et al. is Shephard (2010), who estimates an extended version of the BRV model using pre-reform data and simulates the labor supply and equilibrium effects of the British Working Family Tax reform affecting low income workers.
} 
2010; Addison and Blackburn 2008) and the Current Population Survey (e.g., Neumark and Wascher 2006; Allegretto, Dube and Reich 2011). The QCEW's advantage lies in providing essentially a full census of employment at the county and industry level. The CPS's advantage lies in providing the worker-level demographic data needed to estimate employment effects by age or gender. Neither data source contains the type of longitudinal firm-worker linkages that enables researchers to test hypotheses regarding turnover reductions in response to a minimum wage change.

In this paper we use the QWI, which combines many of the virtues of both the QCEW and the CPS, while also allowing a richer analysis of dynamic responses to minimum wage changes. ${ }^{4}$ The QWI data offer employment counts and average wages by detailed industry at the county level for specified age and gender groupings, and as well quarterly figures for hires, separations and turnover rates. We use five different dependent variables in our empirical analysis: (1) Earnings: Average monthly earnings of employees who worked on the last day of the reference quarter in county $i$. (2) Employment: Number of jobs on the last day of the quarter in county $i$. (3) Accessions (Hires): The number of workers who started a new job in the specified quarter in county $i$. This variable includes new hires as well as workers who have been rehired with the same employer within the last four quarters. (4) Separations: Number of workers whose job with a given employer ended in the specified quarter in county $i$. (5) Turnover rate: Average number of hires and separations as a share of total employment: $\frac{\text { Accessions }+ \text { Separations }}{2 \times \text { Employment }}$

The first two variables are consistent with the data presented in the QCEW, while the three flow variables - hires, separations, and turnover rate - are unique to the QWI. In addition, the QWI offers separate tabulations of these outcome variables calculated only for workers who are employed at the firm for at least one full quarter. ${ }^{5}$ We refer to this sample as workers with "tenure greater than 1 quarter."

Our paper focuses on labor turnover in response to minimum wage changes within a specific low-wage industry or a specified demographic group. Low-wage labor markets have long been recognized as highly volatile, with very short employment spells and frequent shifts between labor market participation and non-participation. Consequently, earnings,

\footnotetext{
${ }^{4}$ The QWI data are produced though a partnership between the U.S. Census Bureau and various state Labor Market Information (LMI) offices. This partnership, called the Local Employment Dynamics (LED) program, combines administrative data from each participating state's unemployment insurance filings (which also make up the current QCEW) with current demographic information from other administrative censuses.Thompson (2009) also uses the QWI data to evaluate the effect of minimum wage on teen and young adult employment. Thompson's primary concern is whether the "bite" of the minimum wage explains the magnitude of the employment effect. In contrast, our focus is on separations and turnover.

${ }^{5}$ More precisely, according to the Census Bureau, the $>1 \mathrm{q}$ hires measure equals the number of workers who began work with an employer in the previous quarter and remain with the same employer in the current quarter; and the $>1 \mathrm{q}$ separations measure equals the number of workers who had a job for at least a full quarter and then the job ended in the current quarter.
} 
employment and turnover calculations may vary considerably with the proportion of workers who begin or complete job spells during the quarter. Thus, we present our empirical estimates for earnings, employment, hires, separations, and turnover for workers "at all tenure levels" as well as for those with "tenure greater than 1 quarter."

\subsection{Sample construction}

State participation in the QWI program varies by year. Four states (IL, MD, WA and WI) began to participate in 1990, with additional states joining during the 1990s and 2000s. The vast majority of states had entered the QWI program by the late 1990s and early 2000s. Consequently, starting the sample in 1990 would generate highly unbalanced panels. Therefore, we limit our sample period to 2001q1 through $2008 \mathrm{q} 4 .^{6}$

\subsubsection{Demographic groups and industries}

We estimate minimum wage effects for two broad employment categories, both of which have been the focus of much previous empirical research and which include high shares of minimum wage workers. The first employment group consists of teens. Using the demographic information contained in the QWI we present minimum wage elasticities for all teens aged 14-18. 7 The second high-impact group is the restaurant industry. In 2006 restaurants employed 29.9 percent of all workers paid within ten percent of the state/federal minimum wage, making restaurants the single largest employer of minimum wage workers at the 3-digit industry level (authors' analysis of the 2006 CPS). Restaurants are also the most intensive user of minimum wage workers, with 33 percent of restaurant workers earning within ten percent of the minimum wage (using 3-digit level industry data). We also provide additional estimates within the restaurant sample by age categories (teens, young adults who are 19-24 years old, and all other adults), and gender and subsector to test for substitution among these groups The QWI does not contain information on race, ethnicity or education levels.

\subsubsection{Contiguous County Pair Sample}

Our empirical strategy is based upon difference-in-difference estimates from a panel of contiguous county pairs that straddle state borders. Our QWI sample consists of the 1,063

\footnotetext{
${ }^{6}$ The dataset we obtained from the Cornell University Virtual Data Repository — which hosts the QWI flat files - included data through 2009q1 at that time. Since the hires, separations and turnover variables with tenure greater than one quarter require information for a leading quarter, the last quarter for which these variables are defined is $2008 \mathrm{q} 4$.

${ }^{7}$ The youngest age category reported in the QWI is 14-18.
} 
counties that border another state. Collectively, these border counties comprise 1,169 unique county pairs. Some of these pairs have a minimum wage differential and others do not. In addition, in any single regression we limit the sample to those counties that have a full panel of disclosed data. As is the case with the QCEW, the QWI does not report values for cells in which too few establishments comprise the sample and/or where the identity of a given establishment could be disclosed. We merge information on overall local unemployment rates and the value of each state's minimum wage in each quarter with the QWI county-pair panel dataset. ${ }^{8}$

What are the effects of restricting our sample to border-county pairs? Table 1 presents the means and standard deviations for our five outcome variables for all 2,960 U.S. counties and for the 1,063 contiguous counties in our border-county pair sample. We display these measures for all private sector employees, all employed teens, and all restaurant workers, and separately as well for workers at all tenure levels and those with at least one quarter of tenure. Depending upon the worker group and tenure level, average earnings are 0.5 to 1 percent lower in the border-county pair sample, while average employment is 7 to 10 percent lower. Hires, separations and turnover rates are virtually identical in both samples. We surmise that the border-county sample is composed of somewhat smaller counties, but this difference is modest. All the other characteristics of the two samples are quite close.

Table 2 presents descriptive statistics for our five outcome variables, both for "all tenure" and "tenure $\geq 1$ quarter," as well as the minimum wage. The sample size for each variable, which differs depending on the industry or demographic group in question, ranges from 28,000 to 66,112 .

\subsection{Empirical Strategy to Estimate Reduced-Form Elasticities}

To measure the impact of minimum wage changes on earnings, employment levels and employment flows, we follow the research design proposed in DLR of generalizing the local case study approach by comparing outcomes from all U.S. counties on either side of a state border. As shown in detail in DLR, this research design has desirable properties for identifying minimum wage effects. Measuring labor market outcomes from an immediately adjacent county provides a better control group, since firms and workers on either side are generally affected by the same idiosyncratic local trends and experiencemacroeconomic shocks at roughly the same time. The inability to control for such trends and shocks can produce highly misleading estimates.

\footnotetext{
${ }^{8}$ We treat the county of San Francisco, California as a separate policy unit and compare it with neighboring counties. San Francisco has a county-level minimum wage that applies to all workers and establishments, analogous to a state minimum wage in every respect.
} 
Our cross-border research design begins with a panel dataset consisting of all contiguous county pairs that straddle a state border. We use two different specifications to estimate the model. Specification 1 includes controls for common-time fixed effects, which we call the "canonical" approach.

(1) $y_{i p t}^{k}=\alpha+\beta \ln \left(M W_{i t}\right)+\delta \ln \left(e m p_{i t}^{T O T}\right)+\gamma \ln \left(\right.$ pop $\left._{i t}\right)+\phi_{i}+\tau_{t}+\epsilon_{i p t}$

Here $y_{i p t}^{k}$ refers to the value of the dependent variable-which could refer to the log of earnings, employment, separations, or hires, or the turnover rate-in county $i$, in countypair $p$, at time $t$, for each of the specific industry or demographic groups $k$ (e.g., restaurant workers or teens). Note that a given county can be part of multiple county pairs if it borders more than one adjacent county. In addition, given the time frame of our panel dataset, a given county can be either a "treated" or "control" unit, depending on the timing of minimum wage changes between the affected states. The coefficient on the minimum wage variable $\ln \left(M W_{i t}\right)$ is the primary coefficient of interest; it is reported in each of the tables below.

Specification 1 also includes controls for the natural log of total private sector employment and population in each county. ${ }^{9}$ The $\phi_{i}$ term represents a county fixed-effect. Crucially, the common time fixed-effects $\tau_{t}$ are assumed to be constant across counties, which rules out possibly heterogeneous trends. ${ }^{10}$

In Specification 1, conditional on covariates and the county fixed effect, all other counties are used as controls for a treated county facing a minimum wage hike-regardless of their geographic locations. In contrast, our preferred identification strategy consists of making a series of localized comparisons within contiguous county pairs. This is represented in Specification 2 below:

(2) $y_{i p t}^{k}=\alpha+\beta \ln \left(M W_{i t}\right)+\delta \ln \left(e m p_{i t}^{T O T}\right)+\gamma \ln \left(\right.$ pop $\left._{i t}\right)+\phi_{i}+\tau_{p t}+\epsilon_{i p t}$

This specification is analogous to Specification 1 in every respect except for the inclusion of a pair-specific time effect $\tau_{p t}$, rather than a common time effect. This change is critical in that minimum wage effects are estimated only using differences-in-differences in the outcome variable within each pair. Thus our identifying assumption for this local specification is is that conditional on covariates and county fixed effects, minimum wage differences within the pair are uncorrelated with the differences in the residual outcome in either county. This is much weaker than the assumpiton in the canonical Specification 1.

Note that the contiguous county pair sample stacks each border county pair, so that a particular county will be in the sample as many times as it can be paired with a neighbor across the border. This property allows us to mean difference all the variables within each pair-period group, avoiding estimating $\tau_{p t}$. Hence, Specification 2 uses the within-pair variation across all pairs and effectively pools the estimates.

\footnotetext{
${ }^{9}$ We use county-level Census Bureau population data, which are reported on an annual basis.

${ }^{10}$ In the remainder of this paper, we will use the term common time effects for $\tau_{t}$.
} 
Since policy is set at the state level, we cluster our standard errors at the state level. However, the presence of a single county in multiple pairs along a border segment induces a mechanical correlation across state pairs, and potentially along an entire border segment. To account for this source of bias, we additionally cluster on the border segment using multi-dimensional clustering (Cameron, Gelbach and Miller 2007).

\section{Empirical Findings}

\subsection{Descriptive statistics}

Since the QWI is relatively unfamiliar to most economists, here we provide some additional descriptive statistics in Table 2 for the workforce at large. As Table 2 indicates, the sample means for the outcome variables vary considerably by age and industry, as well as by tenure level. Earnings levels are much lower among teens, young adults and restaurant workers than among all older workers; women earn less than men; and workers with job tenure $\geq$ 1 quarter earn more than workers with less than one quarter of job tenure. ${ }^{11}$ These are expected patterns. The proportion of workers with less than one quarter of tenure ranges from 31 percent among teens, to 26 percent among limited-service restaurants and 23 percent among full-service restaurants.

Hire, separation and turnover rates also vary with age, industry, gender, and tenure level. Each of these three rates is higher for younger workers than for older workers. Teens, for example, have a turnover rate of 62 percent, followed by 53 percent among young adults, and 18 percent for older adults. The three rates are also higher among restaurant workers than among all workers, and much higher among workers with job tenure of less than one quarter. For differences by age, industry and tenure, each of these variables is inversely correlated with earnings levels: hire, separation and turnover rates are lower among higherpaid workers. These patterns are similar to those found in previous research.

Men have a slightly greater rate of turnover (23 percent) than women (21 percent). However, among workers with job tenure $\geq 1$ quarter, the hire, separation and tenure rates are virtually identical for males and females.

Although not shown in Table 2, the data that underlie the separation rates yield surprising indications of how concentrated separations are in short-tenure jobs. Among all workers, jobs with less than one quarter of tenure account for 10.1 percent of all jobs, but 55.7 percent of all separations. In the restaurant industry, separations are as concentrated in short-term jobs, but such jobs are three times more common than in all industries. In

\footnotetext{
11 Some of these pay differentials reflect differences in hours worked, experience and skill level, but our data do not permit us to quantify these effects.
} 
restaurants, jobs with less than one quarter of tenure account for 31 percent of all jobs and 60.5 percent of all separations. This duration dependence of separation is useful for interpreting the results on the the turnover elasticity in the next section.

\subsection{Main results}

We present in Table 3 our main findings on the effects of minimum wage increases for teens and for restaurant workers. For each group we report estimates for five outcome variables and using two specifications, one with controls for common time effects (the canonical model), and the second with controls for county-pair specific time effects (the preferred model). Both are reported in the table to demonstrate the relevance of our border discontinuity-based research design. The text usually refers to our preferred specification, except when to show how spatial heterogeneity can produce misleading estimates using the canonical model.

We begin by showing that the minimum wage is binding for each of these groups. The estimated effects on average monthly earnings are positive and highly significant-for both specifications and for both groups of workers. For each group of workers, the canonical specifications (cols. 1, 3) yields a somewhat smaller effect on earnings than our preferred border-discontinuity specfication (cols. 2, 4). The elasticity of earnings is 0.161 among all teen workers and 0.213 among all restaurant workers. ${ }^{12}$ These findings put to rest any concerns that restricting the identifying variation to cross-border pairs leads to a lack of actual earnings differential across the treated and control units.

We turn next to the estimated employment effects, shown in the second row of Table 3. We highlight two results in this row. First, although the canonical specification (col. 1) yields an estimated employment effect of -0.200 for teen workers, once we account for spatial heterogeneity the coefficient in border-discontinuity specification (col. 2) is very small in magnitude (-0.039) and it is not significantly different from zero. The canonical estimates on teens are very close to those found by researchers using the CPS and similar models (Neumark and Wascher 2007; Allegretto, Dube and Reich 2010). In other words, we find strong evidence that spatial heterogeneity produces a spurious disemployment effect for teen workers, thereby demonstrating the scope of the disemployment bias among studies using the canonical specification. Second, we replicate the qualititive findings in DLR using the QWI sample: among all restaurant workers the canonical estimate of the employment effect is -0.121 and statistically significant. But accounting for spatial heterogeneity reduces the

\footnotetext{
12 The elasticities for teens and for restaurant workers are extremely close to our estimates for these groups using the CPS for teens (Allegretto, Dube and Reich 2010) and the QCEW for restaurants (Dube, Lester and Reich 2010).
} 
effect (in magnitude) to -0.057 and renders it indistinguishable from zero.

Finally, we consider the estimates of the flow outcomes-hires, separations and turnover rates. The findings here contrast sharply with those on employment levels. As rows three to five of Table 3 indicate, hires, separations and turnover rate fall substantially and significantly with minimum wage increases. For our preferred specifications (columns 2 and $4)$, the separation elasticity is substantial both for teens $(-0.253)$ and for restaurant workers (-0.319). The accession (hires) elasticities are quite similar to the separation elasticitieswhich is consistent with the responses reflecting steady state comparisons. For each group, the estimated effects for separations and hires are smaller for Specification 2 than for Specification 1. This is to be expected because the downward bias in employment estimates in Specification 1 mechanically imparts an analogous bias for the separations and hires elasticities, but not for the turnover rate elasticity, or any other rate elasticities. (The separation rate elasticity is equal to the separation elasticity less the employment elasticity.)

Summarizing to this point, we find that our border-discontinuity estimates find strong positive responses to earnings in response to a minimum wage increase. This increase in earnings is met with a change in employment levels that is indistinguishable from zero. However, we find clear evidence that employment flows (hires and separations) both fall strongly in response to the policy change. And these patterns hold whether we consider a high-impact demographic group (teenagers) or a high-impact industry (restaurants).

\subsection{Robustness checks}

Table 4 presents three robustness checks for our main results, using our preferred specification and estimated for teens and for restaurant workers. One concern is the presence in our sample of geographically large counties, which are located primarily in the western U.S. For these counties, border contiguity need not imply proximity of population centers. As a check, columns labeled 1 and 4 add a restriction for county size $(<2,000$ square miles). This restriction does not substantially affect any of the estimated effects on earnings, employment, hires, separations and turnover rates.

A second concern is that the flow results for teens and restaurant workers may be affected by unobserved overall county labor market trends. To check for this possibility, columns labeled 2 and 5 in Table 4 include the overall private sector level outcome (separation, turnover, etc.) as an additional control. Unlike employment, a disproportionately large share of overall separations and new hires come from the low wage sector. For this reason,

inclusion of the overall private sector flow measure is a particularly tough test. For teens, adding this control reduces the absolute value of the flow coefficients, the hires coefficient becomes insignificant, while separations and turnover estimates retain statistical significance. 
For restaurant workers, adding this control also reduces the estimates somewhat, but they continue to be statistically significant. Overall, we conclude that the reductions in flows in low wage sectors and demographic groups are not primarily driven by unobserved local trends in flows.

The group of columns labeled 3 and 6 in Table 4 report results from a test for the presence of pre-existing trends that might confound the estimates, as well as for possible lagged effects. We estimate a single specification that includes both a one year (4 quarters) lead $\ln \left(M W_{t+4}\right)$ and a one year (4 quarters) lag $\ln \left(M W_{t-4}\right)$, in addition to the contemporaneous minimum wage $\ln \left(M W_{t}\right){ }^{13}$ All three of the coefficients are reported in the table. We do not find any statistically significant (or quantitatively large) leading or lagged terms for any of our outcomes. Moreover, including the leading and lagged minimum wage does not attenuate our statistically significant contemporary coefficients for the flow measures reported in Table 3. These results provide additional internal validity to our research design and rules out the possibility that the large reductions in the flows are driven by pre-existing trends. They also show that the reduction in flows represents a permanent change in response to the policy and not transitional dynamics. The latter observation justifies our use of these elasticities in the structural estimation below.

\subsection{Effects by tenure on the job}

As mentioned during our discussion of the descriptive statistics, turnover generally is concentrated among short-term jobs-those of one-quarter or less. Since not all teens may be in minimum wage jobs (or in jobs whose wages are affected by minimum wage policy), we might expect the effect of minimum wage on separations to have a tenure-specific effect. Lower-tenure workers are, ceteris paribus, more likely to be those who are minimum wage workers. In this section, we provide some additional evidence that is consistentwith the interpretation that minimum wage has a causal effect on separations.

First, if minimum wage increases reduce labor market flows, we would expect to find they also reduce the fraction of workers with such short-term jobs. Columns 1 and 4 of Table 5 provide estimated effects on the fraction short-term, for teens and restaurant workers, respectively. The estimated effect is negative for both groups, although statistically significant only for the restaurant sample. To investigate further how minimum wage effects vary by tenure, we estimate our preferred specification for workers who have at least one quarter of job tenure. ${ }^{14}$ Table 5 displays our previous results for workers at all tenure levels

\footnotetext{
${ }^{13}$ The coefficient for $\ln \left(M W_{t}\right)$ represents the short run elasticity, while the sum of the coefficients for $\ln \left(M W_{t}\right)$ and $\ln \left(M W_{t-4}\right)$ represents the long run elasticity.

${ }^{14}$ The QWI data do not provide breakdowns for tenure longer than one quarter.
} 
(column 2 for teens and 5 for restaurant workers, as well as those who have more than one quarter of tenure (columns 3 and 6 ).

When we limit attention to workers with at least one quarter of job tenure, the earnings estimates for both teens and restaurant workers are somewhat smaller than among workers of all tenure levels and they continue to be statistically significant. The somewhat smaller magnitude of the earnings elasticity for the sample with more tenure is consistent with the idea that higher tenure workers tend to be higher wage workers. Employment effects for this sample are again very small and not significant. Among workers with at least one quarter of tenure, the estimated effects on hires and separations are smaller than among workers of all tenure levels and they are no longer significant.

These findings suggest minimum wage changes seem to reduce turnover more sharply for workers with lower tenure level-precisely those whose wages are more likely to be affected by the policy. However, since the sample of those with less than one quarter of tenure may also be affected by the policy change, we need to be cautious in interpreting these estimates. ${ }^{15}$

\subsection{Labor-labor substitution? Effects on employment shares of dif- ferent demographic groups}

An important question in the minimum wage literature concerns whether higher minimum wages induce employers to substitute away from some demographic groups. Previous researchers, such as Neumark and Wascher (2007), who use the canonical fixed-effects specification and find disemployment effects, also report substitution away from teens and lower skilled workers. Although we do not find disemployment effects, substitution effects might still be present, affecting the shares of different groups in particular jobs.

To address this question directly we report in Table 6 estimates of the impact of minimum wage increases on outcomes for the demographic groups in our key industry-restaurants. The first column reports the employment share of each of the demographic group in the restaurant workforce. The second and third column report the impact on a log point change in the minimum wage on log average earnings (column 2) and share of employment (column 3). Teen workers in restaurants see earnings increases many times greater than adult restaurant workers. Yet, as the table indicates, none of the share - coefficients are significant or

\footnotetext{
${ }^{15}$ If a compositional change in the sample is induced by the minimum wage, a single index model suggests that those changing categories from $<1$ quarter and $>1$ quarter of tenure are likely to have the lowest separation propensity in the former group, and the highest separation propensity in the latter. As a result, the compositional change is likely to make the separation elasticity estimate more negative in both groups. Since we find very strong reductions in separations in the former group and much smaller reductions in the latter, the compositional story is unlikely to fully explain these patterns. However, absent better data, we cannot rule this out.
} 
substantial. The implied share elasticities are modest (under -0.11 in magnitude) and never statistically significant. In all, we do not find any labor-labor substitution along the age and gender categories in our data. We also estimated outcomes separately by age, gender and separately in full and limited service restaurants. The outcomes corresponded to what would be predicted by the relative wage of each demographic group (results not reported in the tables).

More generally, if minimum wage increases lead to a reallocation of workers, one would expect a short term increase in gross flows (separations and accessions). As we saw in Table 4, the data suggests the opposite-both separations and accessions fall immediately and the short and long run changes are quite similar. This lack of labor-labor substitution sharpens the "anomaly" for the competitive model, and hence provides an additional reason to consider models with labor market frictions, which we turn to next. ${ }^{16}$

\section{Structural Estimation using Reduced Form Elasticities}

Our key empirical results suggest that among the most affected population, minimum wage increases lead to sizeable earnings effects, small effects on employment levels, and larger effects on employment flows. In this section we evaluate whether all three effects are jointly consistent with an equilibrium model with search frictions, and whether they are informative about the degree of competition in the labor market. We develop this approach using the Burdett-Mortensen model. BM present a model with search frictions in which employers post wages. Both unemployed and employed workers receive offers. Workers take the new offer if it is greater than either the reservation wage (in the case of an unemployed person), or their present wage (in the case of an employed person). The interaction among firms and workers leads to a non-degenerate equilibrium wage distribution-even though all firms are identical, as are workers' productivity levels.

We choose the BM model for several reasons. First, it provides a useful setting for understanding turnover and separation. As we discuss below, the equilibrium separations are endogenous. The BM model makes joint predictions about effect of minimum wage changes on employment and turnover, which is attractive for our purposes. In the BM model a wage dispersion emerges endogenously, with lower-wage firms facing greater equilibrium churning. By altering the wage distribution, the minimum wage policy can affect equilibrium separation rates. In contrast, in models such as Mortensen-Pissarides (1994) that do not

\footnotetext{
${ }^{16}$ Although not shown in the table, the canonical specification does spuriously suggest substitution away from teens and males and toward older workers and females. These results suggest the importance of controls for spatial heterogeneity when testing for substitution effects, just as is the case for employment overall.
} 
incorporate on-the-job search, the steady-state separation rate turns out to be invariant to the minimum wage policy. Second, BM is the most commonly used dynamic monopsony model, and others such as Manning (2003), draw heavily from the BM model. The competitive case is a limiting case in the BM model, which allows us to consider whether our results are better explained by a labor market that is relatively monopsonistic or relatively competitive. In terms of wage formation, different search models have assumed either wage posting or bargaining; the BM model assumes wage posting. We think this is a realistic feature of the low-wage labor market. For example, Hall and Krueger (2008) present survey evidence that points to wage posting as the most prevalent form in the low-wage U.S. labor market. Moreover, as Mortensen (2003) points out, in the presence of on-the-job search, changing the wage-posting assumption to a wage-bargaining assumption does not change most of the qualitative results of the BM model. For these reasons, we opt to use the BM model to interpret our reduced form empirical findings.

We use the extension of the BM model by BRV, which allows for heterogeneity in both firm-level productivity and workers' reservation wages. We begin by introducing the key features of this model and then describe how we numerically compute the equilibrium average wage, employment level and average separation rate. We then use the reduced form elasticities and pick likely parameter values that best reproduce these elasticities using both maximum likelihood (implemented with simulated annealing) as well as Bayesian estimation with MCMC. Finally, we characterize the extent of friction and market power implied by the reduced-form estimates, simulate the effects of a minimum wage increase, and discuss the resulting implications for understanding the low-wage labor market.

\subsection{Model Setup}

There is a continuum of workers who are heterogeneous in their reservation wages and a continuum of firms that are heterogeneous in productivity. The reservation wage $b$ is distributed according to $H(b)$. Offers arrive at the rate of $\lambda$ to both employed and unemployed workers alike (the offer rate will depend on the measure of surviving businesses as explained below). Matches are destroyed at the rate $\delta$, in which case a worker becomes unemployed. A worker receiving a wage offer can decide to accept it, remain at her existing job if she has one, or remain unemployed (and receive $b$ ). Given the equality of the offer arrival rate for employed and unemployed, this leads to workers accepting all jobs that pay at least $b$. The

parameter $\kappa=\frac{\lambda}{\delta}$ represents the extent of search frictions, since it determines the relative ease of finding out about job opportunities. A $\kappa$ close to zero suggests a lot of friction, while the labor market becomes increasingly competitive as $\kappa$ tends to infinity.

The marginal revenue product of labor $p$ is distributed continuously according to $\Gamma_{0}(p)$, 
the potential productivity distribution. Firms offer possibly different wages, and this wage offer distribution is denoted as $F(w)$. The lowest wage offered by firms, $\underline{w}$, may be equal to or greater than the statutory minimum $w_{\text {min }}$. If the statutory minimum is greater than $p$ for a given firm, that firm will not produce. Consequently, the conditional (on survival) firm productivity distribution is $\Gamma(p)=\frac{\Gamma_{0}(p)}{\bar{\Gamma}_{0}\left(w_{\text {min }}\right)}$. As in BRV, the contact rate $\lambda$ depends on the measure of surviving firms, and hence $\lambda=\lambda_{0} \bar{\Gamma}_{0}\left(w_{\text {min }}\right)$, where $\lambda_{0}$ is the maximal contact rate.

The profits of a firm with productivity $p$ is simply $\pi(p)=(p-w) \cdot l(w)$, where $l(w)$ is the number of workers the firm can recruit for a given wage $w$. A higher $w$ raises the unit labor cost, but reduces the number of workers leaving for a better job and increases the number of recruits.

As shown in Proposition 9 of BRV, under certain regularity condtions, there exists a unique equilibrium wage function $w=K(p)$ that is one-to-one, implying the wage offer distribution is the convolution of the productivity distribution and the wage function: $\Gamma(K(p))$. Higher productivity firms pay higher wages, leading to a nondegenerate offer distribution for identically productive workers. Lower productivity firms pay less, and have a higher separation rate in steady state.

What is this wage function $K(p)$ ? As shown by equation (14) of BRV, it is defined implicitly as ${ }^{17}$ :

(3) $K(p)=p-\left\{\frac{\underline{p}-\underline{w}}{[1+\kappa]^{2}} H(\underline{w})+\int_{\underline{p}}^{p} \frac{H \circ K(x)}{[1+\kappa \bar{\Gamma}(x)]^{2}} d x\right\} \frac{[1+\kappa \bar{\Gamma}(p)]^{2}}{H[K(p)]}$

If there is a binding minimum wage, then $\underline{w}=w_{\min }$. Otherwise $\underline{w}=\operatorname{argmax}_{w}(\underline{p}-$ $w) H(w)$ as shown in Proposition 8 of BRV. The maximum wage is $K(\bar{p})$. We will discuss our specific parameterizations of $\Gamma$ and $H$ below, but if we can numerically solve for $K(p)$, we can then calculate wage offer distribution $\Gamma(w)=\Gamma(K(p))$. And as shown in BRV's Proposition 2, we can also calculate the equilibrium unemployment (or more accurately nonemployment) rate $u$ and the equilibrium wage distribution $G(w)$ as follows:

(4) $u=\left[\frac{1}{1+\kappa} H(\underline{w})+\int_{\underline{w}}^{\bar{w}} \frac{1}{1+\kappa \bar{F}(x)} d H(x)\right]+[1-H(\bar{w})]$

and

(5) $G(w)=\frac{H(w)-[1+\kappa \bar{F}(w)]\left[\frac{1}{1+\kappa} H(\underline{w})+\int_{\underline{w}}^{w} \frac{1}{1+\kappa \bar{F}(x)} d H(x)\right]}{[1+\kappa \bar{F}(w)](1-u)}$

Once we have numerically calculated the functions $K(p)$ and $G(w)$, and the equilibrium unemployment rate $u$, we can also calculate the mean separation rate, mean wages and employment as follows. First, defining $e$ as the employment rate, we can use equation (4) to calculate it:

(6) $e=1-u=H(\bar{w})-\left[\frac{1}{1+\kappa} H(\underline{w})+\int_{\underline{w}}^{\bar{w}} \frac{1}{1+\kappa \bar{F}(x)} d H(x)\right]$

The average wage level can be computed using the function $G(w)$ :

\footnotetext{
${ }^{17}$ Note that following BRV, for any distribution function $V(x), \bar{V}(x)$ is defined as $1-V(x)$.
} 
(7) $E(w)=\int_{\underline{w}}^{\bar{w}} w d G(w)$

To compute the mean separation rate, we begin with the separation rate at a given firm. For a given firm paying wage $w$, the separation rate $s(w)=\delta+\lambda(1-F(w))=\delta+\lambda \bar{F}(w)$. Matches dissolve at an exogenous rate $\delta$ and the firm's workers receive better offers (wage above $w$ ) at a rate $\lambda \bar{F}(w)$. The mean separation rate is the weighted average of the firmspecific separation rates, where the weight comes from the distribution of equilibrium wages $G(w)$.

(8) $E(s(w))=\delta+\lambda \int_{\underline{w}}^{\bar{w}} \bar{F}(w) d G(w)$

We will assume that the distribution of reservation wages $H(w)$ and productivity $\Gamma(w)$ are both normal. The full vector of parameters in the model is then:

$<\lambda_{0}, \delta, \mu_{h}, \sigma_{h}, \mu_{p}, \sigma_{p}, w_{\min }>$. For a given parameter vector, we can numerically iterate on equation (3) to solve for wage function $K(p)$, and then for mean wage $E(w)$, mean separation rate $E(s(w))$, and employment rate $e$. We can also calculate the elasticities of these three variables with respect to the minimum wage by numerically estimating the derivatives of these function at a given minimum wage level. For minimum wage elasticities, it can be shown that $\kappa_{0}=\frac{\lambda_{0}}{\delta}$ is a sufficient statistic for $\lambda_{0}$ and $\delta$. Therefore, for the purpose of our structural estimation, we will define $\Theta=<\kappa_{0}, \mu_{h}, \sigma_{h}, \mu_{p}, \sigma_{p}, w_{\text {min }}>$ as the vector of model parameters in the discussion below.

\subsection{Estimating the Model}

In this section, we use the reduced-form elasticities to pick parameter values for the wageposting model using both classical and Bayesian methods. In particular, we pick the parameters in the model $\Theta=\left\langle\kappa, \mu_{h}, \sigma_{h}, \mu_{p}, \sigma_{p}, \$ 7.25\right\rangle$ that are best able to match the vector of the three key empirical estimates for the teen sample-the average wage elasticity, the separation rate elasticity and the employment elasticity, as well as the sample mean of the minimum to mean wage ratio for teenagers-a measure of equilibrium wage dispersion. ${ }^{18}$ We use the empirical elasticities from the teen sample, as this represents the entire workforce for that demographic group as opposed to workers in a specific industry. Our approach implicitly assumes that the minimum wage elasticities are measuring changes in steady state flows, as opposed to possible transitional dynamics. This assumption is supported by the evidence

\footnotetext{
${ }^{18}$ When we estimated the model with just the three elasticities, our estimate of the labor market friction parameter $\kappa$ was similar, but other parameter estimates were unstable and/or imprecise, and sometimes suggested empirically unreasonable wage distributions. For this reason we use the additional information about the minimum to mean wage ratio in our sample. Since the QWI only reports average earnings, we estimated the minimum to mean wage ratio two ways. In the first approach, which we use for our estimates, we obtain average hours for teens under 19 years of age using the CPS for our sample period to convert the hourly minimum wage to a weekly equivalent. We also calculated the minimum to mean wage ratio for teens using the CPS directly; the results were nearly identical.
} 
in Table 3 that the accession and separation elasticities were quantiatively similar; and that the short and long run elasticities in Table 4 were statistically indistinguishable.

The vector of empirical estimates is denoted as: $\hat{Y}=\left\langle\hat{y_{1}}, \hat{y_{2}}, \hat{y_{3}}, \hat{y_{4}}\right\rangle$

$=\left\langle\frac{\partial E(w)}{\partial w_{\min }} \frac{w_{\min }}{E(w)}, \frac{\partial E(s)}{\partial w_{\min }} \frac{w_{\min }}{E(s)}, \frac{\partial e}{\partial w_{\min }} \frac{w_{\min }}{e}, \frac{w_{\min }}{E(w)}\right\rangle=\langle 0.16,-0.21,-0.04,0.73\rangle$. Note that the separations elasticity (as shown in Table 3) is the sum of the separation rate elasticity (0.21 ) and the employment elasticity $(-0.04)$ and is hence -0.25 . For our estimation, we set the minimum wage level at $\$ 7.25$, the existing federal minimum wage, which is also close to the mean real minimum wage in 2011 dollars over the sample that is used to estimate the minimum wage elasticities. ${ }^{19}$ As mentioned above, for the three elasticties, $\kappa=\frac{\lambda}{\delta}$ is a sufficient statistic for these two variables. Therefore, we set $\delta$ to generate mean sepration rates close to the sample mean. We pay particular attention to the following question: do the empirical elasticities restrict the likely range of the model parameters in general, and the extent of search frictions and wage-setting power in particular?

Our approach is similar to the estimation of DSGE model parameters by matching impulse responses from vector autoregressions (e.g., Christiano, Trabandt, and Walentin 2010). In our case, we will pick parameters to match our reduced-form elasticities. Our approach can also be thought of as a form of indirect inference, which chooses the parameters of a theoretical model to ensure that the the empirical and theoretical estimates of an auxiliary model (in our case elasticities) are as close as possible (e.g., Gourieroux, Monfort, and Renault 1993).

For a given vector of parameters $\Theta$, we can compute the theoretical quantities $Y(\Theta)=$ $\left\langle y_{1}(\Theta), y_{2}(\Theta), y_{3}(\Theta), y_{4}(\Theta)\right\rangle$. Assuming that the estimates are from a large sample, the likelihood of oberving the empirical estimates $\hat{Y}$ for a given vector $\Theta$ can then be written as $p(\hat{Y} \mid \Theta)=\phi\left(\hat{Y}, Y(\Theta), \Sigma_{Y}\right)$. Here $\phi($.$) is the multivariate Normal probability density func-$ tion with the vector of means $Y(\Theta)$, and covariance matrix for the reduced form estimates, $\Sigma_{Y}$. Since the latter is unknown, we proxy $\Sigma_{Y}$ with its empirical counterpart $\hat{\Sigma_{Y}}$. One advantage of our approach over other structural approaches (including a full information maximum likelihood estimation) is that the normality of the likelihood function comes from the central limit theorem, not from any assumption about the distribution of the observations. As long as the reduced-form elasticities were estimated using a large sample, we know the exact form of their joint distribution.

Based on this formulation, one approach is to pick the vector of parameters $\Theta$ that maximizes the $\log$ likelihood $\ln (p(\hat{Y} \mid \Theta))=\ln \left(\phi\left(\hat{Y}, Y(\Theta), \hat{\Sigma_{Y}}\right)\right)$. This limited information maximum likelihood is our preferred approach, which we implement using simulated annealing. We follow a simulation-based approach both because of the complicated nature

\footnotetext{
${ }^{19}$ The average minimum wage around all changes in the statutory minimum over this period was $\$ 7.35$ in May 2011 dollars.
} 
of the likelihood function, and because simulated annealing is less likely to get trapped in local optima than gradient-based methods. We use these estimates to conduct the policy simulations in the next subsection.

We also provide Bayesian estimates of the posterior distribution of the model parameters using Markov Chain Monte Carlo (MCMC). The Bayesian approach is useful for understanding how the empirical elasticities shift one's priors over the key parameters, especially in the context of a small number of elasticities used to fit the model. We use uniform priors over a wide range for each of the five parameters: $\kappa_{0} \sim U[0,100], \mu_{h} \sim U[0,40], \sigma_{h} \sim U[0,40], \mu_{p} \sim$ $U[0,40], \sigma_{p} \sim U[0,40]$. Given uniform priors, the posterior distribution is proportional to the likelihood: $\pi(\Theta \mid \hat{Y})=\frac{p(\hat{Y} \mid \Theta) \cdot \pi(\Theta)}{p(\hat{Y})} \propto p(\hat{Y} \mid \Theta)$. As a consequence, the maximum likelihood estimate obtained using simulated annealing is also an estimate for the mode of the posterior distribution (i.e., the maximum a posteriori probability estimate) if we limit the solution to being within the support of the priors. This is attractive because it allows us to discuss the parameter estimates in a unified way as different attributes of the same posterior density function.

The mechanics of our MCMC and simulated annealing algorithms are quite similar, with one key exception. In both cases, for each iteration $i$, we draw a candidate parameter vector $\Theta_{i}^{c}$ using a random-walk Metropolis algorithm varying one parameter $\theta_{j} \in \Theta$ at a time: $\theta_{i, j}^{c}=\theta_{i-1, j}+s_{j} \epsilon_{i}$. Here $\epsilon_{i}$ is a draw from the standard normal distribution, and $s_{j}$ is a parameter-specific standard deviation whose calibration is described below. Also in both cases, we use the candidate parameter vector $\Theta_{i}^{c}$ to numerically iterate on equation (3) and solve for the wage function, compute the minimum wage elasticities and the minimum to mean wage ratio, $Y\left(\Theta_{i}^{c}\right)$, and then compute the log likelihood $\ln \left(p\left(\hat{Y} \mid \Theta_{i}^{c}\right)\right)$.

For the MCMC algorithm, the candicate vector $\Theta_{i}^{c}$ is accepted if

$\min \left(e^{\left[\ln p\left(\hat{Y} \mid \Theta_{i-1}\right)-\ln p\left(\hat{Y} \mid \Theta_{i}^{c}\right)\right]}, 1\right)>U(0,1)$ and if the candidate vector falls within the support of the prior distribution, where $U(0,1)$ is a draw from the standard uniform distribution. The standard deviations $s_{j}$ are set "on the fly" in a burn-in period of 30,000 draws to attain between 25 and 45 percent acceptance rates for each parameter (in practice this ranged from 24.6 to 46.1 percent, with a mean of 33.9 percent). The post burn-in Markov chain is 70,000 long, and this chain is used to estimate the posterior distribution.

For the simulated annealing algorithm, the acceptance threshold is raised over time to focus in on the most likely parameter vector (in our case also an estimate of the posterior mode) instead of sampling the entire posterior distribution. Here the candidate vector $\Theta_{i}^{c}$ is accepted when $\min \left(e^{\frac{\ln p\left(\hat{Y} \mid \Theta_{i-1}\right)-\ln p\left(\hat{Y} \mid \Theta_{i}^{c}\right)}{T_{i} \cdot}}, 1\right)>U(0,1)$, where $T_{i}=\alpha T_{i-1}$ is a linear cooling schedule with $\alpha \in(0,1)$. As the "temperature" $T_{i}$ is reduced, candidate vectors are rejected more often, until the estimates converge to the estimated optimum. The slower 
the cooling schedule (i.e., the larger is $\alpha$ ), the less likely it is that the algorithm would get trapped in local optima. ${ }^{20}$ We set the initial temperature $T_{0}$ at 4 and use a fairly slow cooling schedule with $\alpha=0.97$. We use the same standard deviations $s_{j}$ for the simulated annealing procedure as in the MCMC (generated during the MCMC burn-in period). Convergence obtained with around 2,000 draws.

\subsection{Estimates of Model Parameters}

Table 7 presents the results for the posterior mode (or MLE) using simulated annealing, as well as the the posterior mean and the highest posterior density (HPD) credible intervals using MCMC. ${ }^{21}$ Figure 1 presents the prior and posterior densities of the parameters. How well do the parameter estimates using the posterior mode match the data? At the fitted values, the model-based average wage, employment and separation elasticities are 0.16, 0.05, and -0.25, respectively; these compare with the empirical elasticities of 0.16, -0.04 and -0.25. The predicted minimum to mean wage ratio is 0.74 , as compared to the empirical mean of 0.73 . Overall, we are able to match the empirical elasticities and our measure of wage dispersion almost exactly.

Arguably the most important parameter for this exercise is $\kappa_{0}$, as it measures the maximal contact rate to job destruction rate ratio, and provides an upper bound on the degree of competition in the labor market. The posterior mode of this parameter (and the MLE estimate) is 5.8. As shown visually in Figure 1, the posterior density of $\kappa_{0}$ is clearly much more concentrated as compared to the uniform prior. The 80 percent HPD credible interval for $\kappa_{0}$ is under 19 , while the 90 percent HPD interval comfortably excludes the prior mean (50). The right skew in the distribution does lead the posterior mean to be larger than the mode.

Since the minimum wage causes some firms to not produce, the equilibrium $\kappa$ is smaller than $\kappa_{0}$; as shown in Table 9 , the posterior mode estimate of $\kappa$ is equal to 4.9 , while the 80 percent HPD interval is under 14, and the 90 percent HPD interval is under 27. Overall, our estimates of $\kappa$ suggest a substantial amount of friction in the low-wage labor market. Interestingly, our posterior mode estimate is quite similar to what Moscarini and PostelVinay (2009) use in their calibration to study macroeconomic fluctuations: their baseline value is $\frac{0.12}{0.025}=4.8$.

Next, we turn to our other parameter estimates. The posterior mode for the mean of the

\footnotetext{
${ }^{20}$ For an example of simulated annealing used in search of the mode of the target distribution, see Chib and Ramamurthy (2010). Use of simulated annealing in optimization is also discussed in Goffe et al. (1994) and Chernozhukov and Hong (2003).

${ }^{21}$ Since we use a fairly limited amount of information to estimate these parameters, we do not report asymptotic standard errors for the MLE
} 
productivity distribution is 8.97 , while the mode for the standard deviation is 1.74 . As we show below in our model simulations using the fitted data, this distribution of productivity suggests small employment losses for most of the range of minimum wages observed in our sample. Figure 1 and the highest probability density intervals show that the density of the productivity parameters are concentrated around the mode and the mean.

In contrast to the parameters on labor market friction and the distribution of productivity, the posterior densities of the reservation wage distribution parameters are quite dispersed. Basically, our elasticity estimates and the minimum to mean wage ratio do not pin down the reservation wage distribution very well.

The imprecision of our inference for these two parameters does not, however, prevent us from drawing conclusions about what the minimum wage effects suggest regarding friction in the labor market. We have already discussed the credible intervals for $\kappa$. We also consider other measures. When evaluated at the fitted parameter values (i.e., at the posterior mode), the average wage-to-productivity ratio is 0.89 , suggesting that monoposonistic wagesetting practices reduce the relevant average wages by around 11 percent, which is similar in magnitude to estimates of union wage effects as well as race and gender wage differentials in the U.S. A related metric for measuring wage-setting power by firms is the firm-level labor supply elasticity. For a given firm in the model, profit maximization implies that the labor supply elasticity is equal to $\frac{w}{p-w}$. Based on our posterior mode estimate, the (employment weighted) measure of the firm-level labor supply elasticity is around 8.5 for a minimum wage of $\$ 7.25$ /hour, although it is lower at 6.5 if the minimum wage were set at $\$ 5.15 /$ hour (the latter results are shown in Table 8). The posterior mean (at $\$ 7.25$ minimum wage) is around 9.3, and the 80 percent HPD intervals for the firm-level labor supply elasticity as shown in Table 9 is $(3.8,14,7)$. Overall, we think a 4 to 10 range likely captures the average firm-level labor supply elasticity in the low-wage labor market (this is also close to the $66 \%$ HPD interval for the measure).

A 4 to 10 range suggets a substantial amount of wage-setting power in the low wage labor market. Although the estimates are somewhat larger than many of the firm-level studies discussed in Ashenfelter, Farber and Ransom (2010), as well as the 2 to 5 range originally posited by Card and Krueger (1995), the discrepancy is not surprising. Many of the firm-based studies often examine larger firms- for whom the model suggests greater monopsony power. In our model, while monopsony power at the larger firms is substantially higher, averaging across the entire low-wage labor market still suggets a sizeable average extent of wage-setting power.

It is also instructive to compare our estimate of the firm-level labor supply elasticity to a "naive" estimate using the separation elasticity alone and treating the policy change as an 
increase in wages in a single firm. As Manning (2003) explains, under certain assumptions the firm-level labor supply elasticity is two times its separation elasticity. Dividing the minimum wage elasticity of separation $(-0.25)$ by the minimum wage elasticity of the average wage (0.14), we would obtain an average wage elasticity of separation of -1.79 , suggesting a labor supply elasticity of $2 \times 1.79=3.6$. This is below the 4 to 10 range for the firm labor supply elasticity. But this is also to be expected, since the "naive" estimate does not account for the rise in wages in some competing firms.

Overall, we want to highlight three conclusions from this exercise. First, the minimum wage elasticities for wages, employment and separations are most consistent with a labor market with a sizeable amount of search friction and monopsony power. By considering a model that embeds the competitive case as a parametric restriction, we are able to directly assess what the minimum wage effects imply about the nature of competition in the low-wage labor market. Second, our consideration of employment flows in addition to employment levels provides us with additional testable propositions, which we use in our estimation exercise. Finally, while structural estimates of the BM-BRV model with such heterogeneity have existed for some time (e.g., BRV 1999), our contribution lies in estimating well-identified reduced-form responses using a quasi-experimental research design and then using these estimates to infer the degree of search frictions suggested by the model. We think our approach provides a fruitful and transparent means to bridge labor market empirics and theory.

Of course, we use only a limited number of reduced-form estimates, which by necessity prevents us from tightly estimating some of the model parameters. Using other information such as firm-level wages and employment flows and other moment conditions would help in this regard. However, our goal was to learn what (if anything) can be inferred from the reduced-form minimum wage elasticities to estimate the extent of search frictions and wage setting power. It is quite telling that the data strongly points us away from a highly competitive market and suggest that frictions are important for understanding minimum wage effects.

\subsection{Policy Simulation}

How does an increase in the minimum wage affect the average wage, overall employment levels and flows, as well as profits and productivity? To answer this question, we numerically simulate the fitted model based on our maximum likelihood estimate (also the posterior mode), while varying the minimum wage from $\$ 5.15$ to $\$ 7.25$. We choose these values for the minimum wage because they equal the two recent levels of the federal minimum wage in nominal dollars. 
We show the simulation findings using two sets of results. In Figure 2, we show how the wage, employment, profit, and separation loci (as a function of firm-level productivity) shift when the minimum wage changes discretely from $\$ 5.15$ to $\$ 7.25$. In Table 8 , we show how mean wage, employment, productivity and separation rates change as we vary the minimum wage from $\$ 5.15$ to $\$ 7.25$.

Figure 2 plots the firm-level wage, employment and separation rate as a function of productivity $p$. As shown in the figure, the higher minimum cuts off the bottom tail of the firm-productivity distribution. At $p=\$ 7.25$, the wage rises to meet the new requirement. However, wages rise at firms with productivity greater than $\$ 7.25$ as well, representing a spillover effect along the wage distribution. Overall, as Table 8 shows, the average wage inceases 3.4 percent, from $\$ 9.38$ to $\$ 9.70$.

Figure 2 also shows that employment falls to zero in firms with productivity between the old and the new minimum wage. Overall, total employment falls by 0.5 percent, implying an average minimum wage elasticity of employment of -0.01 (smaller in magnitude than the marginal elasticity of -0.04). Employment and profits fall in firms with greater productivity. As the (surviving) lower-productivity firms pay higher wages, they create more competitive pressure in the labor market, reducing employment at higher wage firms. This increase in competition occurs in spite of the fact that the contact rate $\lambda=\lambda_{0} \bar{\Gamma}_{0}\left(w_{\text {min }}\right)$ is declining with minimum wage as some firms go out of business. This pro-competitive effect is also reflected in Table 8, which shows a rise in the firm-level labor supply elasticity from 6.5 to 8.5 , indicating a more competitive labor market. Overall profits decline by around 20 percent (results not shown in the table).

As Figure 2 shows, the separation rate is lower at firms with greater productivity (and wage), since they have fewer competitors to whom they lose workers. A higher minimum wage simply truncates the separation rate-productivity locus from the bottom and does not change the shape of the locus. This occurs because a surviving firm with productivity $p$ loses workers to higher-wage competitors at the rate $\lambda \bar{F}(w(p))=\lambda \bar{\Gamma}(p)=$ $\left[\lambda_{0} \bar{\Gamma}_{0}\left(w_{\text {min }}\right)\right]\left[1-\frac{\Gamma_{0}(p)-\Gamma_{0}\left(w_{\text {min }}\right)}{1-\Gamma_{0}\left(w_{\text {min }}\right)}\right]=\lambda_{0} \bar{\Gamma}_{0}(p)$, which is invariant to the minimum wage. By reducing the number of low-productivity firms, a higher minimum wage also reduces the number of high-separation firms and hence tends to reduce the mean separation rate. In our policy experiment, the overall fall in separations, which equals the sum of the decline in the separation rate (3.6 percent) plus the decline in employment ( 0.5 percent), amounts to 4.1 percent.

To sum up, the fitted model suggests that a 41 percent increase in the minimum wage (from $\$ 5.15$ to $\$ 7.25$ ) leads to a 3.4 percent increase in the average wage in the relevant labor force. This wage increase is met with a 0.5 percent reduction in employment, a 0.7 percent 
increase in average productivity due to reallocation of workers, and a 4.1 percent reduction in separations. The relatively small job loss is afforded by the increased competitiveness in the labor market, which reduces profits, as well as the small increase in productivity due to the reallocation of workers across firms.

\section{Discussion and Conclusion}

The contribution of this paper is twofold. First, we provide policy-relevant minimum wage elasticities of employment, earnings and separations for teens as well as for a high impact industry-restaurants. Second, we use well-identified reduced-form elasticities along with a simple measure of equilibrium wage dispersion to estimate the parameters of an equilbrium model with wage posting. Our approach allows us to directly assess the importance of search frictions in the low-wage labor market, especially in mediating the effects of minimum wage increases.

Our border discontinuity design shows that even though teen and restaurant employment levels remain stable in response to a minimum wage increase, employment flows fall substantially. Average separations, hires and turnover rates decline significantly among teen workers and restaurant establishments. The changes are immediate (within one quarter) of the minimum wage increase and they persist. Our data also permits us to test directly whether the absence of an employment effect in the restaurant sector simply reflects the substitution of older workers for teens. We do not detect any such labor-labor substitution in restaurants in response to minimum wage increases. These findings clarify and strengthen the evidence for the argument that the no-disemployment finding is indeed an anomaly for the purely competitive model.

A number of researchers (Card and Krueger 1995; Ashenfelter, Farber and Ransom 2010) have suggested that the anomaly may be explainable in a dynamic monopsony model. In this model, higher wages attract more workers to the firm and fewer quit, which may even increase the profit-maximizing level of employment. This simple firm-level dynamic monopsony model thus suggests that a minimum wage increase may reduce labor market flows rather than employment levels.

However, the simple firm-level dynamic monopsony story does not provide clear implications for equilibrium responses, as it does not take into account interactions among firms and workers. To account for such equilbrium effects, we use the Burdett-Mortensen wage-posting framework, which explicitly models these interactions. The equilibrium wage dispersion in the model causes excess churning in the labor market. We advance the literature by linking well-identified reduced-form estimates from the teen labor market to the 
model's parameters using both LIML and Bayesian approaches.

The fitted model is able to rationalize sizeable wage effects, small employment effects and larger separation effects. The mean separation rate tends to decline with minimum wage increases, as the minimum wage shifts the employment distribution away from high-turnover, low-wage firms to low-turnover, high-wage ones. The posterior densities clearly point to the importance of search friction and monopsony in this labor market: our results point to average firm-level labor supply elasticities in the 4 to 10 range. Our policy simulations show that moving the minimum wage up from $\$ 5.15$ to $\$ 7.25$ generates a 3.4 percent increase in the average teen wage, while reducing employment by less than 0.4 percent and reducing separations by around 2 percent. Even though some businesses may stop hiring, the increased competition among surviving businesses mostly compensates for that employment loss.

Future work could build on our approach by considering a wider set of minimum wage responses, including across different types of firms-a fruitful avenue for future research using firm-level data. Moreover, the model also has implications for how minimum wage affects different types of flows-employment to non-employment, as well as employment to employment transitions. Finally, the model could also be expanded to allow for effects on output prices. Aaronson and French (2006) argue that their findings on price pass-through cast doubt on the monopsony model as an explanation for small employment changes. Future research could examine the possible role of price pass-through by further expanding the BRV model with a price-setting component.

Our results indicate that the low-wage labor market in the United States contains a substantial amount of search friction and that it deviates from a purely competitive description. Therefore, the effects of minimum wage policies tend to be more complicated. By compressing the wage distribution, minimum wage increases can reduce the churning that characterize the low-wage segment of the labor market. As a consequence, a properly designed minimum wage policy has the possibility of improving the structure and functioning of the low wage labor market without substantially affecting employment. 


\section{References}

[1] Aaronson, Daniel and Eric French 2007. "Product Market Evidence on the Employment Effects of the Minimum Wage." Journal of Labor Economics 25, 2: 167-200.

[2] Allegretto, Sylvia, Arindrajit Dube and Michael Reich 2011. "Do Minimum Wages Really Reduce Teen Employment? Accounting for Heterogeneity and Selectivity in State Panel Data." Industrial Relations 50, 5: 205-40.

[3] Angrist, Joshua D., and Jörn-Steffen Pischke 2010. "The Credibility Revolution in Empirical Economics: How Better Research Design Is Taking the Con out of Econometrics." 24, 2: 3-30.

[4] Ashenfelter, Orley, Henry Farber and Michael Ransom 2010. "Modern Models of Monopsony in Labor Markets: A Brief Survey." Journal of Labor Economics 28, 2: 203-10.

[5] Bontemps, Christian, Jean-Marc Robin and Gerard van den Berg 1999. "An Empirical Equilibrium Job Search Model With Search on the Job and Heterogeneous Workers and Firms." International Economic Review 40, 4: 1039-74.

[6] Brochu, Pierre, and David Green 2011. "The Impact of Minimum Wages on Quit, Layoff and Hiring Rates." Unpublished paper. Universities of Ottawa and British Columbia.

[7] Burdett, Kenneth and Dale Mortensen 1998. "Wage Differentials, Employer Size, and Unemployment." International Economics Review 39: 257-73.

[8] Cameron, Colin, Jonah Gelbach, and Douglas Miller 2006. "Robust Inference with Multi-Way Clustering." NBER Working Paper No. T0327.

[9] Card, David and Alan Krueger 1995. Myth and Measurement. Princeton: Princeton University Press.

[10] Chernozhukov, Victor and Han Hong 2003. "An MCMC Approach to Classical Estimation." Journal of Econometrics 115, 2: 293-346.

[11] Chib, Siddhartha and Srikanth Ramamurthy 2010. "Tailored Randomized-block MCMC Methods with Application to DSGE Models." Journal of Econometrics 155: 19-38.

[12] Chowdry, Haroon, Costa Meghir and Jonathan Shaw 2009. "Investigating the Impact of the Minimum Wage Regime on the Labor Market Behaviour of Young Workers: Moving Towards a Structural Dynamic Approach." Report for the Low Pay Commission. London: Institute for Fiscal Studies. 
[13] Christiano, Lawrence, Mathias Trabandt and Karl Walentin 2010. "DSGE Models for Monetary Policy Analysis." NBER Working Paper 16074.

[14] Chernozhukov, Victor and Han Hong 2003. "An MCMC approach to Classical Estimation." Journal of Econometrics 115, 2: 293-346.

[15] Dube, Arindrajit, William Lester and Michael Reich 2010. "Minimum Wage Effects Across State Borders: Estimates Using Contiguous Counties." Review of Economics and Statistics 92, 4: 945-64.

[16] Dube, Arindrajit, Suresh Naidu and Michael Reich 2007. "The Economic Effects of a Citywide Minimum Wage." Industrial and Labor Relations Review 60, 4: 522-43.

[17] Eckstein, Zvi and Kenneth Wolpin 1990. "Estimating a Market Equilibrium Search Model from Panel Data on Individuals." Econometrica 58, 4: 783-808.

[18] Fairris, David 2005. "The Impact of Living Wages on Employers: A Control Group Analysis of the Los Angeles Ordinance." Industrial Relations 44, 1: 84-105.

[19] Flinn, Christopher 2006. "Minimum Wage Effects on Labor Market Outcomes under Search, Matching, and Endogenous Contact Rates." Econometrica 74, 4: 1013-62.

[20] Flinn, Christopher and James Mabli 2009. "On-the-Job Search, Minimum Wages, and Labor Market Outcomes in an Equilibrium Bargaining Framework." Unpublished paper, Department of Economics, New York University.

[21] Goffe, William L., Gary .D. Ferrier, and John Rogers. 1994. "Global Optimization of Statistical Functions with Simulated Annealing." Journal of Econometrics 60: 65-99.

[22] Gourieroux, Christian, Alain Monfort, and Eric Renault 1993. "Indirect Inference." Journal of Applied Econometrics 8: S85-118.

[23] Hall, Robert E. and Alan B. Krueger 2008. "Wage Formation between Newly Hired Workers and Employers: Survey Evidence." NBER Working Paper 14329.

[24] Howes, Candace 2005. "Living Wages and Retention of Homecare Workers in San Francisco." Industrial Relations 44, 1: 139-63.

[25] Manning, Alan 2003. Monopsony in Motion: Imperfect Competition in Labor Markets. Princeton: Princeton University Press. 
[26] _-___-______-_2010. "Imperfect Competition in the Labor Market." In Orley Ashenfelter and David Card eds. Handbook of Labor Economics vol. 4. Amsterdam: North-Holland.

[27] Mortensen, Dale 2003. Wage Dispersion: Why are Similar Workers Paid Differently? Cambridge, MA: MIT Press.

[28] Mortensen, Dale and Christopher Pissarides 1994. "Job Creation and Job Destruction in the Theory of Unemployment." Review of Economic Studies 61, 3: 397-415.

[29] Moscarini, Guiseppe and Fabien Postel-Vinay 2008. "The Timing of Labor Market Expansions: New Facts and a New Hypothesis", NBER Macroeconomics Annual 23: $1-51$.

[30] Neumark, David and Mark Wascher 2007. "Minimum Wages, the Earned Income Tax Credit and Employment: Evidence from the Post-Welfare Reform Era." NBER Working Paper 12915.

[31] Portugal, Pedro and Ana Rute Cardoso 2006. "Disentangling the Minimum Wage Puzzle: An Analysis of Worker Accessions and Separations." Journal of the European Economic Association 4, 5: 988-1013.

[32] Reich, Michael, Peter Hall and Ken Jacobs 2005. "Living Wage Policies at San Francisco Airport: Impacts on Workers and Businesses." Industrial Relations 44, 1: 106-38.

[33] Shepard, Andrew 2010. "Equilibrium Search and Tax Reform." Unpublished paper, Department of Economics, Princeton University.

[34] Sims, Christopher A. 2010. "But Economics Is Not an Experimental Science." Journal of Economic Perspectives. 24, 2: 59-68.

[35] Thompson, Jeffrey 2009. "Using Local Labor Market Data to Re-Examine the Employment Effects of the Minimum Wage." Industrial and Labor Relations Review 62, 3: 343-66. 
Figure 1

Prior and Posterior Densities from MCMC Estimation
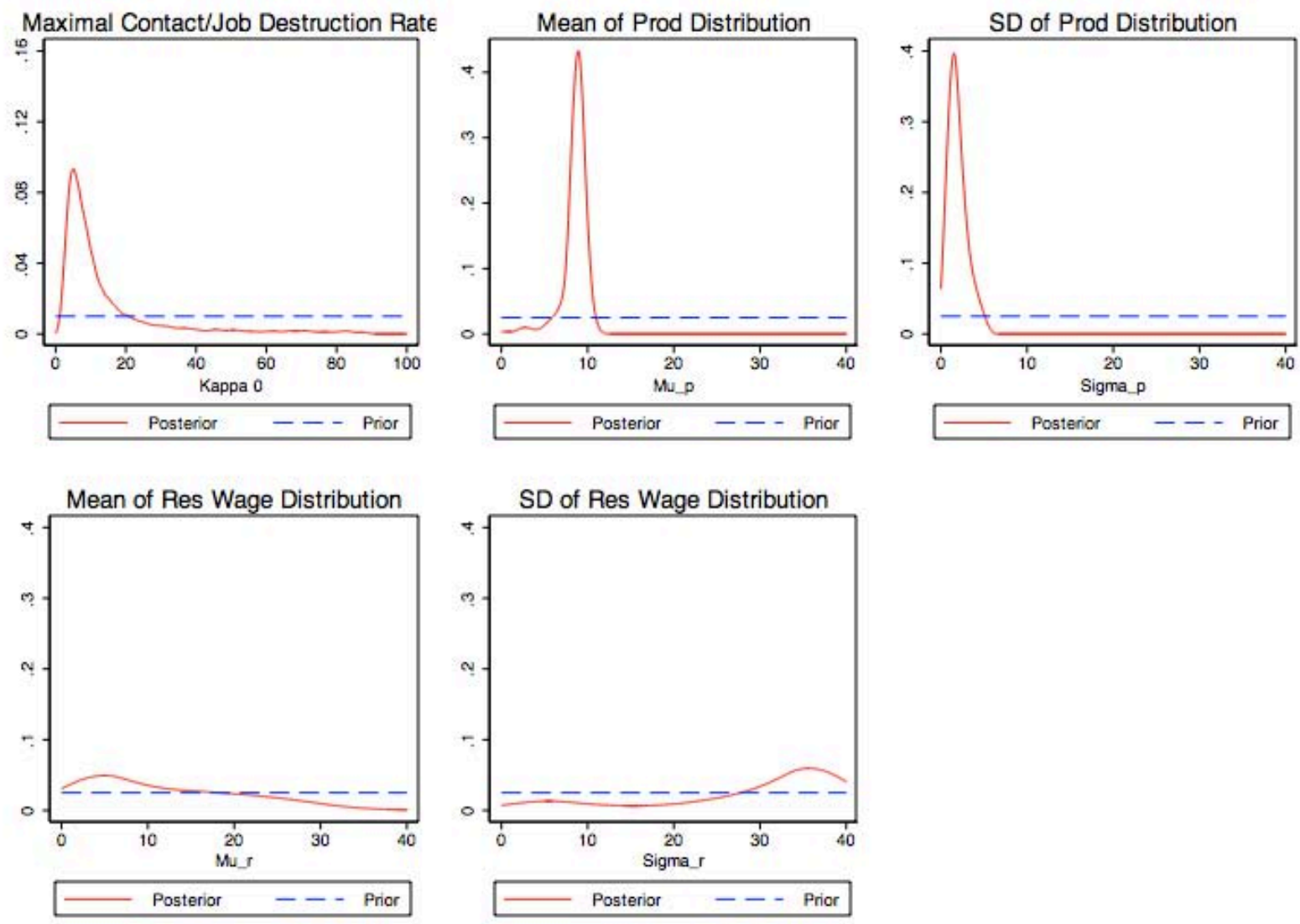

Notes. The figure shows the (uniform) prior and the posterior distribution of the model parameters: the ratio of the maximal contact rate to job destruction rate $\left(\kappa_{0}\right)$, the mean and standard deviations of the reservation wage distribution, $\left(\mu_{r}, \sigma_{r}\right)$ and the mean and standard deviations of the firm productivity distribution, $\left(\mu_{r}, \sigma_{r}\right)$. The posterior densities were estimated using MCMC based on the likelihood of observing the empirical minimum wage elasticities of average wage, employment, and separation of $0.16,-0.04$ and -0.25 , respectively, and a minimum to average wage ratio of 0.73 for a given parameter value. 


\section{Figure 2}

\section{Outcomes by Firm-Productivity Levels - Raising the Minimum Wage from \$5.15 to \$7.25}
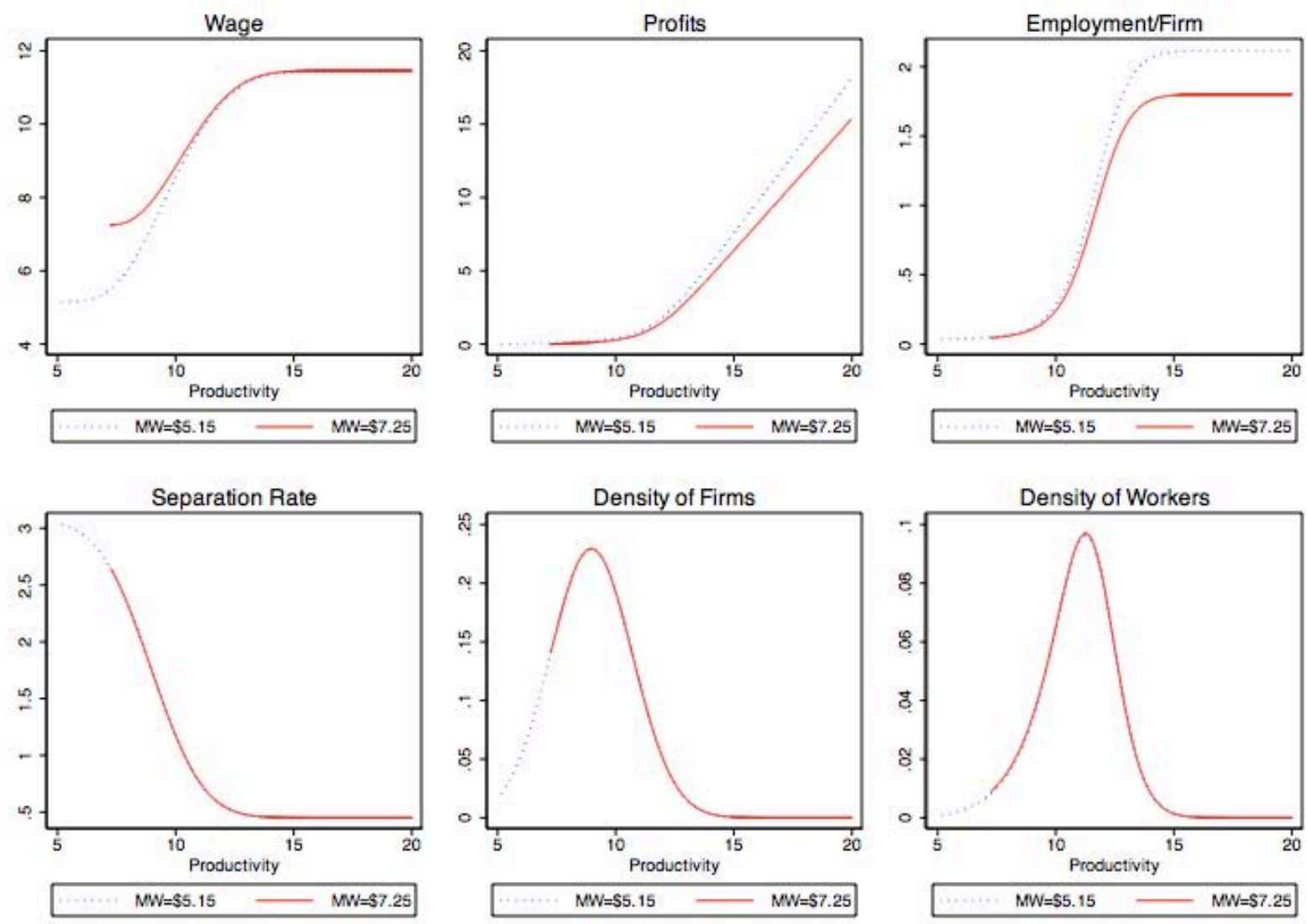

Notes. The policy experiment simulates the fitted model based on the MLE/posterior mode estimates from column 1 of Table 7. The figure shows firm level outcomes (wage, profits, employment and separation rate), density of firms, and density of workers by firm-productivity level. The dotted lines in blue represents the outcomes when the minimum wage is $\$ 5.15 /$ hour, while the solid lines in red represent the outcomes when the minimum wage is set at $\$ 7.25 /$ hour. 
Table 1

\section{Comparing Samples in the QWI Data}

\begin{tabular}{|c|c|c|c|c|c|c|}
\hline & \multicolumn{3}{|c|}{ All Counties Sample } & \multicolumn{3}{|c|}{ Contiguous County Pair Sample } \\
\hline & $\begin{array}{c}\text { Total } \\
\text { Private } \\
\text { Sector } \\
\end{array}$ & $\begin{array}{c}\text { All } \\
\text { Teens }\end{array}$ & Restaurants & $\begin{array}{c}\text { Total } \\
\text { Private } \\
\text { Sector } \\
\end{array}$ & $\begin{array}{c}\text { All } \\
\text { Teens }\end{array}$ & Restaurants \\
\hline $\begin{array}{l}\text { All } \\
\text { Monthly }\end{array}$ & & & & & & \\
\hline $\begin{array}{l}\text { Earnings } \\
\quad(\text { st. dev })\end{array}$ & $\begin{array}{c}2,326 \\
585\end{array}$ & $\begin{array}{l}457 \\
134\end{array}$ & $\begin{array}{l}789 \\
238\end{array}$ & $\begin{array}{c}2,323 \\
587\end{array}$ & $\begin{array}{l}453 \\
131\end{array}$ & $\begin{array}{l}782 \\
221\end{array}$ \\
\hline $\begin{array}{l}\text { Employment } \\
\text { (st. dev) }\end{array}$ & $\begin{array}{l}40,564 \\
143,386\end{array}$ & $\begin{array}{l}1,383 \\
3,952\end{array}$ & $\begin{array}{l}2,945 \\
9,558\end{array}$ & $\begin{array}{l}38,055 \\
125,310\end{array}$ & $\begin{array}{l}1,290 \\
3,272\end{array}$ & $\begin{array}{l}2,748 \\
8,097\end{array}$ \\
\hline $\begin{array}{l}\text { Hire rates } \\
(s t . d e v)\end{array}$ & $\begin{array}{l}0.224 \\
0.092\end{array}$ & $\begin{array}{l}0.686 \\
0.382\end{array}$ & $\begin{array}{l}0.440 \\
0.194\end{array}$ & $\begin{array}{l}0.230 \\
0.091\end{array}$ & $\begin{array}{l}0.697 \\
0.369\end{array}$ & $\begin{array}{l}0.446 \\
0.189\end{array}$ \\
\hline $\begin{array}{l}\text { Separation rates } \\
\text { (st. } d e v)\end{array}$ & $\begin{array}{l}0.217 \\
0.072\end{array}$ & $\begin{array}{l}0.557 \\
0.264\end{array}$ & $\begin{array}{l}0.432 \\
0.149\end{array}$ & $\begin{array}{l}0.222 \\
0.074\end{array}$ & $\begin{array}{l}0.562 \\
0.225\end{array}$ & $\begin{array}{l}0.440 \\
0.181\end{array}$ \\
\hline $\begin{array}{l}\text { Turnover Rate } \\
\text { (st. dev) }\end{array}$ & $\begin{array}{l}0.220 \\
0.074\end{array}$ & $\begin{array}{l}0.618 \\
0.327\end{array}$ & $\begin{array}{l}0.433 \\
0.158\end{array}$ & $\begin{array}{l}0.220 \\
0.073\end{array}$ & $\begin{array}{l}0.618 \\
0.350\end{array}$ & $\begin{array}{l}0.433 \\
0.159\end{array}$ \\
\hline $\begin{array}{l}\text { Tenure }>1 \\
\text { quarter }\end{array}$ & & & & & & \\
\hline $\begin{array}{l}\text { Monthly Earnings } \\
\text { (st. dev) }\end{array}$ & $\begin{array}{c}2,548 \\
650\end{array}$ & $\begin{array}{l}562 \\
176\end{array}$ & $\begin{array}{l}939 \\
276\end{array}$ & $\begin{array}{c}2,537 \\
647\end{array}$ & $\begin{array}{l}557 \\
175\end{array}$ & $\begin{array}{l}929 \\
269\end{array}$ \\
\hline $\begin{array}{l}\text { Employment } \\
\text { (st. dev) }\end{array}$ & $\begin{array}{l}35,139 \\
125,217\end{array}$ & $\begin{array}{c}952 \\
2,761\end{array}$ & $\begin{array}{l}2,248 \\
7,558\end{array}$ & $\begin{array}{l}32,992 \\
109,714\end{array}$ & $\begin{array}{c}888 \\
2,269\end{array}$ & $\begin{array}{l}2,095 \\
6,366\end{array}$ \\
\hline $\begin{array}{l}\text { Hire rates } \\
(\text { st. } d e v)\end{array}$ & $\begin{array}{l}0.104 \\
0.034\end{array}$ & $\begin{array}{l}0.308 \\
0.085\end{array}$ & $\begin{array}{l}0.200 \\
0.056\end{array}$ & $\begin{array}{l}0.106 \\
0.036\end{array}$ & $\begin{array}{l}0.308 \\
0.085\end{array}$ & $\begin{array}{l}0.204 \\
0.059\end{array}$ \\
\hline $\begin{array}{l}\text { Separation rates } \\
\text { (st. dev) }\end{array}$ & $\begin{array}{l}0.102 \\
0.041\end{array}$ & $\begin{array}{l}0.221 \\
0.082\end{array}$ & $\begin{array}{l}0.198 \\
0.081\end{array}$ & $\begin{array}{l}0.104 \\
0.046\end{array}$ & $\begin{array}{l}0.224 \\
0.082\end{array}$ & $\begin{array}{l}0.204 \\
0.087\end{array}$ \\
\hline $\begin{array}{l}\text { Turnover Rate } \\
\text { (st. dev) }\end{array}$ & $\begin{array}{l}0.103 \\
0.028\end{array}$ & $\begin{array}{l}0.265 \\
0.077\end{array}$ & $\begin{array}{l}0.202 \\
0.084\end{array}$ & $\begin{array}{l}0.103 \\
0.027\end{array}$ & $\begin{array}{l}0.266 \\
0.078\end{array}$ & $\begin{array}{l}0.203 \\
0.081\end{array}$ \\
\hline $\begin{array}{l}\text { Number of } \\
\text { counties } \\
\text { Number of county } \\
\text { pairs }\end{array}$ & & 2,960 & & & 1,063 & \\
\hline
\end{tabular}

Notes. Sample means are reported for all counties in the US and for all contiguous border county pairs with a full balanced panel of observations. Standard deviations are shown in italics below the means. Monthly earnings are in nominal dollars. Turnover rates are quarterly. Sample sizes vary by demographic group, industry and tenure and ranges from 28,000 to 66,112. Sample period is from 2001Q1 through 2008Q4. Data Source: Quarterly Workforce Indicators. 
Table 2

Descriptive Statistics

\begin{tabular}{|c|c|c|c|c|c|c|}
\hline Dependent Variable & Teens & $\begin{array}{l}\text { Young } \\
\text { Adults }\end{array}$ & $\begin{array}{c}\text { Adults } \\
25+\end{array}$ & Females & Males & $\begin{array}{c}\text { Restaurant } \\
\text { Workers }\end{array}$ \\
\hline \multicolumn{7}{|l|}{ All } \\
\hline \multirow[t]{2}{*}{ Monthly Earnings } & 453 & 952 & 2,559 & 1,784 & 2,856 & 782 \\
\hline & 131 & 220 & 594 & 452 & 741 & 221 \\
\hline \multirow[t]{2}{*}{ Employment } & 1,290 & 2,055 & 40,679 & 18,779 & 19,276 & 2,748 \\
\hline & 3,272 & 5,736 & 126,186 & 61,549 & 63,831 & 8,097 \\
\hline \multirow[t]{2}{*}{ Hiring Rate } & 0.697 & 0.551 & 0.189 & 0.219 & 0.243 & 0.446 \\
\hline & 0.369 & 0.234 & 0.061 & 0.089 & 0.104 & 0.189 \\
\hline \multirow[t]{2}{*}{ Separation Rate } & 0.562 & 0.524 & 0.189 & 0.211 & 0.234 & 0.440 \\
\hline & 0.225 & 0.165 & 0.057 & 0.072 & 0.084 & 0.181 \\
\hline \multirow[t]{2}{*}{ Turnover Rate } & 0.618 & 0.527 & 0.182 & 0.209 & 0.232 & 0.433 \\
\hline & 0.350 & 0.169 & 0.055 & 0.071 & 0.082 & 0.159 \\
\hline \multicolumn{7}{|l|}{ Tenure $>1$ quarter } \\
\hline \multirow[t]{2}{*}{ Monthly Earnings } & 557 & 1,144 & 2,774 & 1,953 & 3,125 & 929 \\
\hline & 175 & 259 & 638 & 508 & 809 & 269 \\
\hline \multirow[t]{2}{*}{ Employment } & 888 & 1,453 & 37,217 & 16,337 & 16,655 & 2,095 \\
\hline & 2,269 & 4,104 & 113,957 & 54,021 & 55,753 & 6,366 \\
\hline \multirow[t]{2}{*}{ Hiring Rate } & 0.308 & 0.245 & 0.091 & 0.105 & 0.107 & 0.204 \\
\hline & 0.085 & 0.060 & 0.026 & 0.038 & 0.039 & 0.059 \\
\hline \multirow[t]{2}{*}{ Separation Rate } & 0.224 & 0.227 & 0.092 & 0.103 & 0.105 & 0.204 \\
\hline & 0.082 & 0.071 & 0.026 & 0.051 & 0.049 & 0.087 \\
\hline \multirow[t]{2}{*}{ Turnover Rate } & 0.266 & 0.237 & 0.091 & 0.102 & 0.104 & 0.203 \\
\hline & 0.078 & 0.063 & 0.020 & 0.030 & 0.030 & 0.081 \\
\hline
\end{tabular}

Notes. Sample means are reported for all contiguous border county pairs with a full balanced panel of observations. Standard deviations are shown in italics below the means. Monthly earnings are in nominal dollars. Turnover rates are quarterly. Teens are of ages 14-18; young adults are of ages 19-24. Sample sizes vary by demographic group, industry and tenure and ranges from 28,000 to 66,112. Sample period is from 2001Q1 through 2008Q4. Data Source: Quarterly Workforce Indicators. 
Table 3

Minimum Wage Elasticities for Earnings, Employment Level and Flows

\begin{tabular}{|c|c|c|c|c|}
\hline \multirow[b]{2}{*}{ Dependent Variable } & \multicolumn{2}{|c|}{ Teens } & \multicolumn{2}{|c|}{ Restaurant Workers } \\
\hline & (1) & (2) & (3) & (4) \\
\hline In Earnings & $\begin{array}{c}0.107^{* *} \\
(0.048)\end{array}$ & $\begin{array}{c}0.161^{* *} \\
(0.064)\end{array}$ & $\begin{array}{c}0.169^{* * *} \\
(0.035)\end{array}$ & $\begin{array}{c}0.213^{* * *} \\
(0.072)\end{array}$ \\
\hline In Employment & $\begin{array}{l}-0.200^{* * *} \\
(0.066)\end{array}$ & $\begin{array}{l}-0.039 \\
(0.065)\end{array}$ & $\begin{array}{l}-0.121^{* * *} \\
(0.043)\end{array}$ & $\begin{array}{l}-0.057 \\
(0.104)\end{array}$ \\
\hline In Hires & $\begin{array}{l}-0.454^{* * *} \\
(0.089)\end{array}$ & $\begin{array}{l}-0.224^{* *} \\
(0.111)\end{array}$ & $\begin{array}{l}-0.466^{* * *} \\
(0.081)\end{array}$ & $\begin{array}{l}-0.342^{* *} \\
(0.172)\end{array}$ \\
\hline In Separations & $\begin{array}{l}-0.463^{* * *} \\
(0.096)\end{array}$ & $\begin{array}{c}-0.253^{* *} \\
(0.102)\end{array}$ & $\begin{array}{l}-0.468^{* * *} \\
(0.076)\end{array}$ & $\begin{array}{c}-0.319^{* *} \\
(0.133)\end{array}$ \\
\hline In Turnover Rate & $\begin{array}{l}-0.266^{* * *} \\
(0.066)\end{array}$ & $\begin{array}{l}-0.194^{* *} \\
(0.079)\end{array}$ & $\begin{array}{l}-0.327^{* * *} \\
(0.072)\end{array}$ & $\begin{array}{c}-0.257^{* *} \\
(0.123)\end{array}$ \\
\hline Controls: & & & & \\
\hline Common time effects & $\mathrm{Y}$ & & $\mathrm{Y}$ & \\
\hline Pair-specific time effects & & $\mathrm{Y}$ & & $\mathrm{Y}$ \\
\hline
\end{tabular}

Notes. Sample sizes in regressions range from 46,944 to 59520, depending on sample (due to nondisclosure policy). All regressions include controls for natural log of county population and total private sector employment. Specifications 1 and 2 provide estimates for all teens aged 14-18 regardless of industry. Specifications 3-4 are limited to all workers in the restaurant industry (NAICS 722). All samples and specifications include county fixed-effects. Specifications 1 and 3 include common time period fixed-effects. For specifications 2 and 4, period fixed-effects are interacted with each county-pair. Robust standard errors, in parentheses, are clustered at the state and border segment levels for all regressions. Significance levels are indicated by: ${ }^{*}$ for $10 \%,{ }^{* *}$ for $5 \%$, and ${ }^{* * *}$ for $1 \%$. 
Table 4

Minimum Wage Elasticities - Robustness Checks

\begin{tabular}{|c|c|c|c|c|c|c|c|c|c|c|}
\hline \multirow[b]{3}{*}{ Dependent variable } & \multicolumn{5}{|c|}{ Teens } & \multicolumn{5}{|c|}{ Restaurant Workers } \\
\hline & \multirow[t]{2}{*}{ (1) } & \multirow{2}{*}{$(2)$} & \multicolumn{3}{|c|}{ (3) } & \multirow[t]{2}{*}{ (4) } & \multirow{2}{*}{ (5) } & \multicolumn{3}{|c|}{$(6)$} \\
\hline & & & $\ln M W_{t+4}$ & $\ln M W_{t}$ & $\ln M W_{t-4}$ & & & $\ln M W_{t+4}$ & $\ln M W_{t}$ & $\ln M W_{t-4}$ \\
\hline In Earnings & $\begin{array}{l}0.193^{* * *} \\
(0.063)\end{array}$ & $\begin{array}{c}0.158^{* *} \\
(0.065)\end{array}$ & $\begin{array}{c}-0.047 \\
(0.053)\end{array}$ & $\begin{array}{c}0.105 \\
(0.087)\end{array}$ & $\begin{array}{c}-0.012 \\
(0.047)\end{array}$ & $\begin{array}{c}0.193^{* *} \\
(0.083)\end{array}$ & $\begin{array}{l}0.212^{* * *} \\
(0.071)\end{array}$ & $\begin{array}{c}0.033 \\
(0.067)\end{array}$ & $\begin{array}{l}0.224^{* *} \\
(0.099)\end{array}$ & $\begin{array}{c}0.010 \\
(0.056)\end{array}$ \\
\hline In Employment & $\begin{array}{l}-0.022 \\
(0.074)\end{array}$ & $\begin{array}{c}-0.039 \\
(0.065)\end{array}$ & $\begin{array}{c}0.051 \\
(0.066)\end{array}$ & $\begin{array}{c}-0.012 \\
(0.085)\end{array}$ & $\begin{array}{c}0.026 \\
(0.077)\end{array}$ & $\begin{array}{c}-0.038 \\
(0.106)\end{array}$ & $\begin{array}{l}-0.057 \\
(0.104)\end{array}$ & $\begin{array}{c}0.069 \\
(0.066)\end{array}$ & $\begin{array}{c}-0.017 \\
(0.106)\end{array}$ & $\begin{array}{c}-0.013 \\
(0.128)\end{array}$ \\
\hline ln Hires & $\begin{array}{l}-0.242^{*} \\
(0.133)\end{array}$ & $\begin{array}{c}-0.154 \\
(0.100)\end{array}$ & $\begin{array}{c}-0.052 \\
(0.096)\end{array}$ & $\begin{array}{l}-0.243^{*} \\
(0.144)\end{array}$ & $\begin{array}{c}-0.021 \\
(0.149)\end{array}$ & $\begin{array}{l}-0.323^{*} \\
(0.193)\end{array}$ & $\begin{array}{l}-0.292^{*} \\
(0.169)\end{array}$ & $\begin{array}{l}-0.108 \\
(0.115)\end{array}$ & $\begin{array}{l}-0.429^{*} \\
(0.220)\end{array}$ & $\begin{array}{c}-0.058 \\
(0.196)\end{array}$ \\
\hline In Separations & $\begin{array}{l}-0.277^{* *} \\
(0.117)\end{array}$ & $\begin{array}{l}-0.193^{* *} \\
(0.091)\end{array}$ & $\begin{array}{c}-0.061 \\
(0.100)\end{array}$ & $\begin{array}{l}-0.312^{* *} \\
(0.145)\end{array}$ & $\begin{array}{c}0.052 \\
(0.122)\end{array}$ & $\begin{array}{l}-0.316^{* *} \\
(0.148)\end{array}$ & $\begin{array}{l}-0.294^{* *} \\
(0.137)\end{array}$ & $\begin{array}{l}-0.025 \\
(0.098)\end{array}$ & $\begin{array}{l}-0.354^{*} \\
(0.179)\end{array}$ & $\begin{array}{c}-0.059 \\
(0.137)\end{array}$ \\
\hline In Turnover Rate & $\begin{array}{l}-0.212^{* *} \\
(0.093)\end{array}$ & $\begin{array}{l}-0.129^{*} \\
(0.070)\end{array}$ & $\begin{array}{l}-0.118 \\
(0.092)\end{array}$ & $\begin{array}{l}-0.252^{* *} \\
(0.112)\end{array}$ & $\begin{array}{c}-0.037 \\
(0.107)\end{array}$ & $\begin{array}{l}-0.264^{*} \\
(0.147)\end{array}$ & $\begin{array}{l}-0.222^{*} \\
(0.118)\end{array}$ & $\begin{array}{l}-0.125 \\
(0.109)\end{array}$ & $\begin{array}{c}-0.347^{* *} \\
(0.173)\end{array}$ & $\begin{array}{c}-0.047 \\
(0.151)\end{array}$ \\
\hline Controls: & & & & & & & & & & \\
\hline $\begin{array}{l}\text { County size }<2000 \text { sq. mi. } \\
\text { All priv. sector } \ln \text { (outcome) } \\
\text { Lead and lag } \ln (\mathrm{MW})\end{array}$ & $\mathrm{Y}$ & $\mathrm{Y}$ & $\mathrm{Y}$ & $\mathrm{Y}$ & $\mathrm{Y}$ & $\mathrm{Y}$ & $\mathrm{Y}$ & $\mathrm{Y}$ & $\mathrm{Y}$ & $\mathrm{Y}$ \\
\hline
\end{tabular}

Notes. Sample sizes in regressions range from 50,912 to 58,848. All regressions include controls for log of county population and pairspecific time effects. Specifications 1-3 provide estimates for all teens 14-18 regardless of industry. Columns 4-6 are limited to all workers in the restaurant industry (NAICS 722). Columns 1 and 6 restrict the sample to counties of less than 2000 square miles. Columns 2 and 5 include as controls the value of the dependent variable for all workers in the county's private sector (i.e. rather than the group in focus, e.g., teens). Specifications 3 and 6 include a 4-quarter lead and lag in the minimum wage to control for pre-existing trends and delayed effects. All samples and specifications include county pair-specific time effects. Robust standard errors, in parentheses, are clustered at the state and border segment levels for all regressions. Significance levels are indicated by: ${ }^{*}$ for $10 \%,{ }^{* *}$ for $5 \%$, and ${ }^{* * *}$ for $1 \%$. 
Table 5

Minimum Wage Elasticities - Effects by Tenure

\begin{tabular}{|c|c|c|c|c|c|c|}
\hline \multirow{2}{*}{$\begin{array}{l}\text { Dependent } \\
\text { Variable }\end{array}$} & \multicolumn{3}{|c|}{ Teens } & \multicolumn{3}{|c|}{ Restaurant Workers } \\
\hline & (1) & (2) & (3) & (4) & (5) & (6) \\
\hline $\begin{array}{l}\text { Fraction Short- } \\
\text { Term }(\text { tenure }<1 q)\end{array}$ & $\begin{array}{r}-0.026 \\
(0.018)\end{array}$ & All & Tenure $>1 q$ & $\begin{array}{l}-0.039^{* *} \\
(0.020)\end{array}$ & All & Tenure $>1 q$ \\
\hline In Earnings & & $\begin{array}{c}0.161^{* *} \\
(0.064)\end{array}$ & $\begin{array}{r}0.135^{*} \\
(0.068)\end{array}$ & & $\begin{array}{l}0.213^{* * *} \\
(0.072)\end{array}$ & $\begin{array}{l}0.167^{* *} \\
(0.071)\end{array}$ \\
\hline In Employment & & $\begin{array}{l}-0.039 \\
(0.065)\end{array}$ & $\begin{array}{l}-0.002 \\
(0.072)\end{array}$ & & $\begin{array}{l}-0.057 \\
(0.104)\end{array}$ & $\begin{array}{c}0.003 \\
(0.108)\end{array}$ \\
\hline In Hires & & $\begin{array}{l}-0.224^{* *} \\
(0.111)\end{array}$ & $\begin{array}{l}-0.147 \\
(0.098)\end{array}$ & & $\begin{array}{l}-0.342^{* *} \\
(0.172)\end{array}$ & $\begin{array}{l}-0.058 \\
(0.113)\end{array}$ \\
\hline In Separations & & $\begin{array}{l}-0.253^{* *} \\
(0.102)\end{array}$ & $\begin{array}{l}-0.113 \\
(0.073)\end{array}$ & & $\begin{array}{l}-0.319^{* *} \\
(0.133)\end{array}$ & $\begin{array}{l}-0.028 \\
(0.119)\end{array}$ \\
\hline In Turnover Rate & & $\begin{array}{l}-0.194^{* *} \\
(0.079)\end{array}$ & $\begin{array}{l}-0.096 \\
(0.087)\end{array}$ & & $\begin{array}{l}-0.257^{* *} \\
(0.123)\end{array}$ & $\begin{array}{l}-0.148 \\
(0.108)\end{array}$ \\
\hline
\end{tabular}

Notes. Sample sizes in regressions range from 38,080 to 65,689 , depending on sample. All regressions include controls for natural log of county population, total private sector employment and pair-specific time effects. Specifications 1-3 provide estimates for all teens 14-18 in the private sector. Specifications 4-6 provide estimates for all restaurant workers. All samples and specifications include county fixed-effects as well as period fixed-effects interacted with each county-pair. Robust standard errors, in parentheses, are clustered at the state and border segment levels for all regressions. Significance levels are indicated by: ${ }^{*}$ for $10 \%,{ }^{* *}$ for $5 \%$, and ${ }^{* * *}$ for $1 \%$. 


\section{Labor-Labor Substitution within Restaurants}

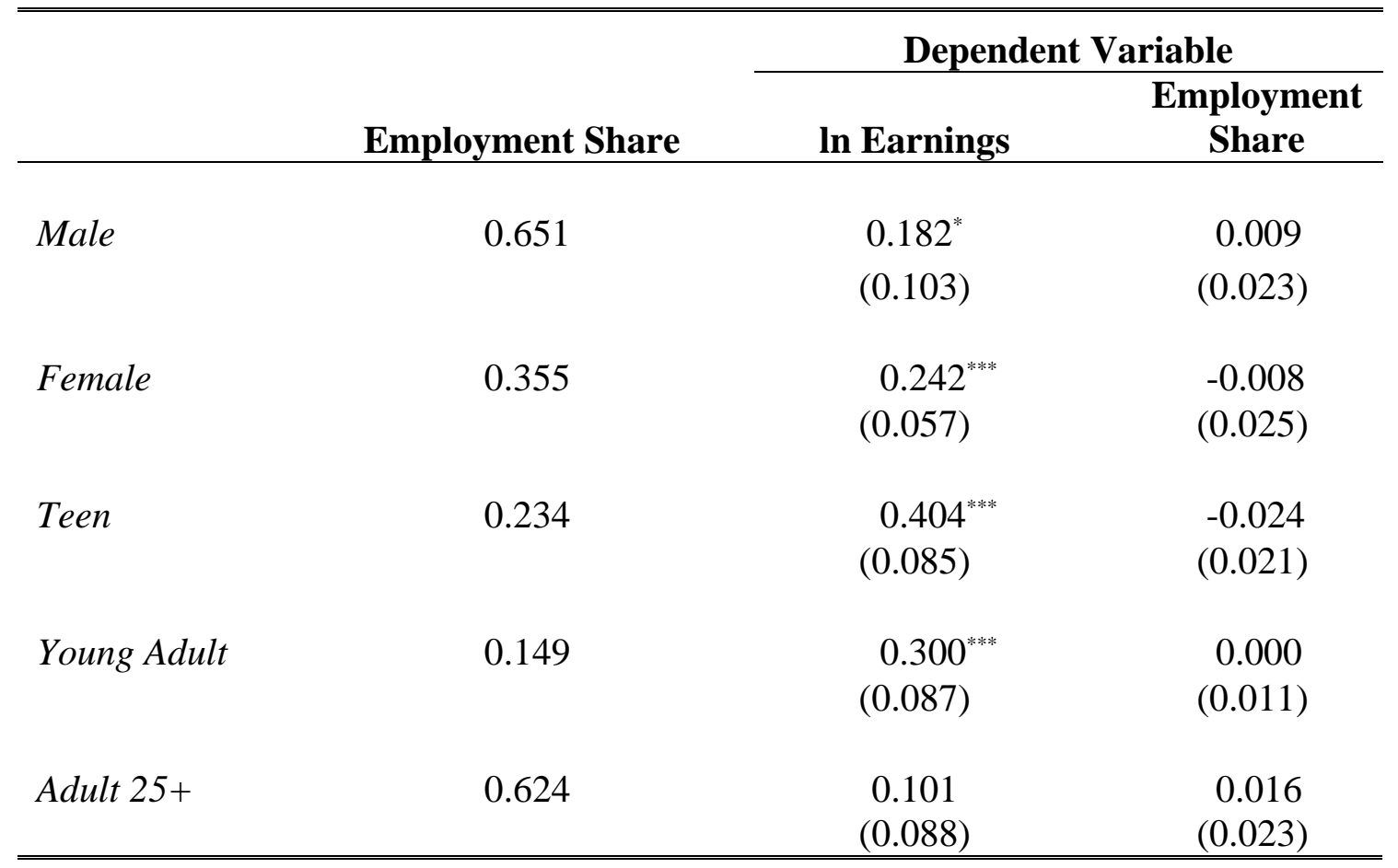

Notes. Column 1 reports the employment share of each demographic group in the overall restaurant workforce. Columns 2 and 3 report the regression coefficient associated with log of the minimum wage. In column 2, the outcome is the log of average earnings; the coefficient is, therefore, the minimum wage elasticity of average earnings. In column 3 , the outcomes are the demographic group's share of overall restaurant employment. Teens are of ages 14-18; young adults are of ages 19-24. All regressions include controls for natural log of county population, total private sector employment and pair-specific time effects. Sample sizes in regressions range from 37,504 to 56,736, depending on sample. Robust standard errors, in parentheses, are clustered at the state and border segment levels for all regressions. Significance levels are indicated by: ${ }^{*}$ for $10 \%,{ }^{* *}$ for $5 \%$, and ${ }^{* * *}$ for $1 \%$. 
Table 7

Parameter Estimates and Predicted Minimum Wage Elasticities

\begin{tabular}{|c|c|c|c|c|}
\hline & $\begin{array}{c}\text { MLE/Posterior } \\
\text { Mode }\end{array}$ & $\begin{array}{l}\text { Posterior } \\
\text { Mean }\end{array}$ & 80\% HPD & 90\% HPD \\
\hline \multicolumn{5}{|l|}{ Parameter Estimates: } \\
\hline$\kappa_{o}$ & 5.82 & 10.07 & $(2.01,18.51)$ & $(1.73,33.00)$ \\
\hline$\mu_{r}$ & 21.58 & 4.78 & $(0.00,20.28)$ & $(0.00,25.08)$ \\
\hline$\sigma_{r}$ & 30.20 & 6.23 & $(20.61,39.99)$ & $(7.10,40.00)$ \\
\hline$\mu_{p}$ & 8.97 & 8.53 & $(7.94,10.09)$ & $(7.08,10.59)$ \\
\hline$\sigma_{\mathrm{p}}$ & 1.74 & 4.19 & $(0.66,2.93)$ & $(0.56,3.75)$ \\
\hline \multicolumn{5}{|l|}{ Equilibrium Quantities: } \\
\hline $\begin{array}{l}\text { Average Firm Labor Supply } \\
\text { Elasticity }[(p-w) / w]\end{array}$ & 8.49 & 9.31 & $(3.76,14.73)$ & $(3.42,20.10)$ \\
\hline $\begin{array}{l}\text { Equilibrium contact-to-job } \\
\text { destruction ratio }(\kappa)\end{array}$ & 4.88 & 7.14 & $(0.75,9.11)$ & $(0.63,17.47)$ \\
\hline \multicolumn{5}{|c|}{ Predicted Minimum Wage Elasticities and Wage Dispersion: } \\
\hline Average wage elasticity & 0.16 & 0.09 & & \\
\hline Employment elasticity & -0.05 & -0.05 & & \\
\hline Separation elasticity & -0.25 & -0.32 & & \\
\hline $\begin{array}{l}\text { Minimum-to-Mean Wage } \\
\text { Ratio }\end{array}$ & 0.74 & 0.70 & & \\
\hline
\end{tabular}

Notes. The top panel reports two sets of estimates. Column 1 reports the MLE for the parameters using simulated annealing, while columns 2-4 report the posterior mean and $80 \%$ and $90 \%$ highest posterior density credible intervals using MCMC. Given the uniform priors, the ML estimate is also an estimate of the posterior mode. The primitives of the model are the ratio of maximal contact rate to job destruction rate $\left(\kappa_{i}\right)$, the mean and standard deviations of the reservation wage distribution, $\left(\mu_{r}, \sigma_{r}\right)$ and the mean and standard deviations of the firm productivity distribution, $\left(\mu_{r}, \sigma_{r}\right)$. In the middle panel, we report the MLE/posterior mode, posterior mean, and highest posterior density intervals of $(p-w) / w$, which is the firmlevel labor supply elasticity, and $\kappa$ which is the equilibrium ratio of contact rate to job destruction rate evaluated at a minimum wage of $\$ 7.25$. In the bottom panel, we report the model generated minimum wage elasticities (of average wage, employment and separation) and the minimum-to-mean wage ratio using both the MLE/posterior mode and the posterior mean parameter estimates. The three empirical elasticities used to fit the model are $0.16,-0.04$ and -0.25 , respectively; the sample mean of the minimumto-mean wage ratio is 0.73 . 
Table 8

Policy Experiment: Raising the Minimum Wage from $\$ 5.15$ to $\$ 7.25$

\begin{tabular}{|c|c|c|}
\hline & MW=5.15 & $M W=7.25$ \\
\hline Average wage & $\$ 9.38$ & $\$ 9.70$ \\
\hline Average productivity & $\$ 10.90$ & $\$ 10.98$ \\
\hline Average wage to productivity ratio & 0.86 & 0.89 \\
\hline $\begin{array}{l}\text { Average firm-level labor supply } \\
\text { elasticity }\end{array}$ & 6.47 & 8.49 \\
\hline Employment to population ratio & 0.854 & 0.851 \\
\hline Average separation rate & 0.427 & 0.408 \\
\hline
\end{tabular}

Notes. The policy experiment simulates the fitted model based on the MLE/posterior mode estimates from column 1 of Table 9. The first column reports the results from a simulation using a minimum wage of $\$ 5.15 /$ hour, while the second column's results use a minimum wage of $\$ 7.25 /$ hour. The average wage, average productivity and average separation rate are all employment-weighted averages across firms. The wage to productivity ratio $(w / p)$ and the average firm-level labor supply elasticity $(p-w) / p$ are calculated analogously. 